\title{
Thermal Performance Optimization of Double and Triple Glazing Systems for Slovenian Climate Conditions
}

\author{
Anita Prapotnik Brdnik
}

Citation: Prapotnik Brdnik, A. Thermal Performance Optimization of Double and Triple Glazing Systems for Slovenian Climate Conditions. Sustainability 2021, 13, 11857. https: / / doi.org/10.3390/su132111857

Academic Editors: Víctor Yepes, Ignacio J. Navarro Martínez and Antonio J. Sánchez-Garrido

Received: 7 September 2021

Accepted: 22 October 2021

Published: 27 October 2021

Publisher's Note: MDPI stays neutral with regard to jurisdictional claims in published maps and institutional affiliations.

Faculty of Civil Engineering, Transportation Engineering and Architecture, University of Maribor, Smetanova Ulica 17, 2000 Maribor, Slovenia; anita.prapotnik@um.si

\begin{abstract}
Glazing elements are an important part of the thermal envelope of a building. Therefore, good thermal performance of glazing elements can improve indoor comfort and reduce annual maintenance costs and $\mathrm{CO}_{2}$ (carbon dioxide) emissions by reducing heat loss. Reducing heat loss through glazing elements during the heating season can be achieved by combining low thermal transmittance with high solar heat gain. Using standardized calculation methods and measured climate data for three Slovenian locations representing typical continental, mountainous and Mediterranean climates, this study predicts the best combination of optical properties (emissivity, transmittance and reflectance) of glass panes in double and triple glazing systems that contribute to minimal heat loss. It was found that for the double glazing system, the minimum heating and cooling demand for buildings with low solar gains or high solar gains and applied shading is achieved by an inner pane with high transmittance without low-emissivity coating, and an outer pane with low-emissivity coating with minimum possible emissivity. In Maribor and Portorož climatic zones, the panes with low emissivity coating should be used as inner panes in buildings with high solar gains. For triple glazing, the minimum heating and cooling requirements are achieved with two or three panes with low emissivity. For buildings with low solar gains, an emissivity of the coating of 0.03 is preferable, but for buildings with high solar gains, lower emissivity values should be used.
\end{abstract}

Keywords: heating demand; cooling demand; thermal transmittance; solar heat gain; double glazing; triple glazing; transmittance; low emissivity coating; Slovenian climate conditions

\section{Introduction}

Windows represent an important element of the building envelope, providing daylight, views of the external environment, and natural ventilation [1]. As these factors play an important role in indoor comfort [2-4], glass elements are becoming increasingly important, leading to the development of buildings with large areas of the building envelope covered with glass elements, such as glass buildings [5] and buildings with double-skin facades [6,7]. Since building energy consumption is responsible for $20 \%$ to $40 \%$ of $\mathrm{CO}_{2}$ emissions [8], efforts to reduce heat loss through glazing systems are of great importance. Indeed, a poorly insulated fenestration system can significantly increase the heat loss of a building. On the other hand, transparent surfaces such as glazing can allow the building to gain additional heat through the greenhouse effect.

The thermal performance of insulating glazing is determined by the heat transfer coefficient $(U)$ and the total solar transmittance $(g)$. The heat transfer coefficient indicates the ability of the glazing to reduce heat loss. On the other hand, total solar transmittance indicates the ability of the glazing to trap solar energy. Since heat always flows from a higher temperature to a lower temperature, it is recommended to keep the heat transfer coefficient as low as possible, regardless of the geographical location of the building, the orientation of the glazing and the time of year. On the other hand, incident solar radiation always heats the interior of the building. Consequently, a high total solar transmittance reduces heat loss in cold climates, but can lead to overheating in hot climates. In wellinsulated buildings with a large window area, a high total solar transmittance can also 
lead to overheating in cold climates [9]. Consequently, the best combination of total solar transmittance and heat transfer coefficient depends on various factors such as geographical location, climate and orientation of fenestration.

The total solar transmittance and heat transfer coefficient depend on the characteristics of the glazing, such as the number of glass panes, the gas used in the gaps, and the properties of the glass panes and glass coatings. Double and triple glazing are most commonly used for building fenestration. However, in systems such as double skin facades, a combination of single panes and/or standard insulating glass is used, resulting in effective quadruple or even multiple glazing to achieve a lower heat transfer coefficient. The gaps between the glass panes are often filled with argon or krypton to reduce heat loss by convection. Additional energy savings can be achieved by using partitions in the gap space and by partially evacuating the gas [10]. Glass surfaces can be tinted to change the color and optical properties of a glass. Various coatings can be applied to glass panes, including static coating types with different combinations of emissive, reflective, and transmissive properties (reflective, low-emissivity, solar control, or self-cleaning coatings) or dynamic coating types that change their properties in response to external stimuli, such as electrochromic, thermochromic, or gas-chromic coatings [9,11].

Research by Sbar et al. [12] on dynamic coating types show that electrochromic coatings can significantly reduce energy consumption. In addition, research by Dussault et al. and Taveres et al. $[13,14]$ show that dynamic coating types provide the best results when cooling is required $[13,14]$. According to Aldawoud et al. and Jamroznik et al. [15,16], dynamic coatings are more effective in energy savings than various other shading elements.

Studies by Papaefthimiou et al., Linag et al., Saeli et al., Allen et al. and Hoffmann et al. [17-21] show that thermocromic coatings are best suited for hot climates. The study by Saeli et al. shows that coatings with low transition temperature are more suitable for fenestration [19]. However, the study by Liang et al. shows that this may not be the case when thermochromic coatings are used in cold climates as they can significantly reduce solar gain [18]. The combined use of electrochromic and thermochromic coatings was investigated by Detsi et al. [1]. It was shown that the combination of both coatings in triple-glazed windows can lead to energy savings in both hot and cold climates.

Low-emissivity coatings can significantly reduce the heat transfer coefficient of glazing. Their optical properties are such that they have low emissivity in the infrared range, reducing heat transfer by radiation at long wavelengths. On the other hand, they can have higher or lower transmittance for short wavelengths, resulting in glass panes with high, medium or low total solar transmittance $[9,22,23]$. There are two basic types of low-emissivity coatings: sputtered or soft coatings and pyrolytic or hard coatings. Sputtered coatings are thinner, have lower emissivity, but are not durable in the presence of moisture and contact. Therefore, they must be sealed within a double or triple glazing. Hard coatings, on the other hand, have higher emissivity, are thicker, but more durable. Low-emissivity coatings and their application in different climates have been studied by Aguilar et al., Li et al., Kumar et al., and Laouuadu et al. [24-27]. The study by Kumar et al. [26] showed that the gray reflective glass has the highest cost savings in annual net cooling and heating for all orientations across three climatic regions in India. The study by Aguilar et al. [24] showed that for Mexican climate, the combination of clear glass and reflective glass provided the highest energy benefits. The study by Li et al. [25] showed that the use of coatings in the climate of Hong Kong can lead to energy savings and that the best results are obtained when the coatings are applied to clear glass rather than tinted glass. The study of Laouadi et al. showed than in winter period in Canada, energy can be saved by using the low-emissivity coatings.

In this paper, we will investigate the energy efficiency of double and triple glazing with argon gas filling between the panes. Different combinations of glazing panes with different emissivity values will be analyzed in order to find the optimal combination of total solar transmittance and heat transfer coefficient in three different geographical locations in Slovenia with three different climatic conditions: Maribor, Kredarica and Portorož. Maribor is located 
in the north-eastern part of Slovenia at an altitude of about $260 \mathrm{~m}$ and has continental climate. Kredarica is located in the northwestern part of Slovenia at an altitude of about $2500 \mathrm{~m}$ and is the highest meteorological station in Slovenia with a typical mountain climate. Portorož is located in the southern part of Slovenia on the Mediterranean Sea at an altitude of about $30 \mathrm{~m}$ and has typical Mediterranean climate. Slovenian climate cones have lower average temperatures compared to India and Hong Kong, but higher than in Canada, so the results of previous mentioned studies cannot be directly applied to Slovenian climate conditions. Double and triple glazing with argon gas filling were chosen for the study, as these types of glazing are the most widely used in Slovenia. The extensive database of glass panes available on the European market is used for the analysis. The database includes about 1000 different glass panes with different thicknesses, tints and static coatings. The energy efficiency of the glazing units is evaluated for eight orientation settings at each of the three sites to determine the most energy efficient combination of glass panes.

Section 2 describes the method used to calculate annual heating and cooling energy requirements for glazing units. In Section 3 we give an overview of the optical properties of the window panes available on the European market. In Section 4 the results are given and discussed, while the conclusions are given in Section 5.

\section{Methodology}

Glazing systems are compared based on their annual heating and cooling energy demand per square meter of glazing. The calculation of annual heating and cooling demand of glazing is based on the standardized method for fenestration systems described in [28], with some simplifications. Since only glazing systems are compared to find the optimal pane composition, the effects of window frames, thermal bridges and ventilation are not considered. Indeed, these effects affect all glazing systems of the same type (double or triple glazing) in the same way. Potential impacts of these effects on the results is mentioned in conclusions. The annual energy demand for heating $\left(P_{H}\right)$ and cooling $\left(P_{C}\right)$ per square meter of glazing is calculated by adding the monthly contributions:

$$
P_{H}=\sum_{m=1}^{12} P_{H, m} \quad P_{C}=\sum_{m=1}^{12} P_{C, m}
$$

where the monthly energy demand for heating $\left(P_{H, m}\right)$ and cooling $\left(P_{C, m}\right)$ is calculated as follows:

$$
\begin{aligned}
& P_{H, m}=f_{H}, m\left(U\left(\Theta_{i, H}-\Theta_{e}\right) t-\eta_{H} g Q_{s o l, m}\right) \\
& P_{C, m}=f_{C}, m\left(F g Q_{s o l, m}-\eta_{C} U\left(\Theta_{i, C}-\Theta_{e}\right) t\right) .
\end{aligned}
$$

The heat transfer coefficient $U$ and the total solar transmittance $g$ depend on the properties of the glazing system and are calculated according to the procedures described in Sections 2.2 and 2.3, respectively. The heating temperature is set to $\Theta_{i, H}=20^{\circ} \mathrm{C}$, the cooling temperature is set to $\Theta_{i, C}=24.5^{\circ} \mathrm{C}$ [29], while the average outdoor temperatures for the month $\Theta_{e}$ are given in Section 2.1. The energy density of incident solar radiation for month $m$ is denoted by $Q_{s o l, m}$ and is given in Section 2.1, while $t$ denotes the duration of a month. During the heating season, the solar heat gain can be reduced by shading elements with shading factor $F$. The fraction of a month that falls in the cooling or heating season $\left(f_{H, m}\right.$ and $f_{C, m}$, respectively) and gain and loss utilization factors $\left(\eta_{H}\right.$ and $\eta_{C}$, respectively) depend on the building characteristics. More precisely, they depend on the total heating and cooling demand of the building and the time constant of the building. The fractions of a month belonging to a cooling or heating season are calculated as $f_{H, m}=Q_{H, m} /\left(Q_{H, m}+Q_{C, m}\right)$ and $f_{C, m}=Q_{C, m} /\left(Q_{H, m}+Q_{C, m}\right)$, where $Q_{H, m}$ and $Q_{C, m}$ are the total heating and cooling demand of a building, respectively. The values of the gain and loss utilization factors are determined using the procedure described in Appendix A of [28].

To keep the analysis as general as possible, the results are presented and discussed for two limiting cases: buildings with low solar gains (poorly insulated buildings, and/or 
buildings with a small ratio of window areas) and buildings with high solar gains (well insulated buildings and/or buildings with a large ratio of window areas). In the first case, the duration of the heating and cooling season is determined as a function of the monthly average temperature. Months with an average temperature below $20^{\circ} \mathrm{C}$ are defined as part of the heating season and months with average temperatures above $24.5^{\circ} \mathrm{C}$ are defined as part of the cooling season. In the second case, the total heat loss and gain are assumed to be equal to the heat loss and gain trough glazing.

\subsection{Meteorological Data}

The average outdoor temperatures and heat flux rates of incident solar radiation are taken from the measured meteorological data available in [30]. The meteorological data are summarized in Tables 1-3.

Table 1. Climate data for Maribor (Slovenia) [30].

\begin{tabular}{|c|c|c|c|c|c|c|c|c|c|c|c|c|}
\hline Month & 1 & 2 & 3 & 4 & 5 & 6 & 7 & 8 & 9 & 10 & 11 & 12 \\
\hline \multicolumn{13}{|c|}{$T_{1}$-average temperature $\left[{ }^{\circ} \mathrm{C}\right], T_{2}$-average highest day temperature $\left[{ }^{\circ} \mathrm{C}\right]$} \\
\hline$T_{1}$ & -0.2 & 1.7 & 6.0 & 10.8 & 15.8 & 19.0 & 21.0 & 20.3 & 15.7 & 10.7 & 5.1 & 0.9 \\
\hline$T_{2}$ & 3.9 & 6.6 & 11.4 & 16.2 & 21.3 & 24.4 & 26.6 & 26.1 & 21.4 & 16.0 & 9.2 & 4.4 \\
\hline \multicolumn{13}{|c|}{$\begin{array}{l}\text { Energy density of incident solar radiation falling on } \\
\text { a vertically set pane during one month period measured in }\left[\mathrm{Wh} / \mathrm{m}^{2}\right]\end{array}$} \\
\hline $\mathbf{N}$ & 474 & 582 & 720 & 1009 & 1175 & 1357 & 1188 & 969 & 834 & 690 & 584 & 494 \\
\hline NE & 504 & 649 & 996 & 1438 & 1789 & 1870 & 1804 & 1564 & 1200 & 823 & 644 & 521 \\
\hline $\mathrm{E}$ & 972 & 1257 & 1721 & 2068 & 2414 & 2353 & 2436 & 2286 & 1894 & 1357 & 1101 & 955 \\
\hline SE & 1901 & 2244 & 2366 & 2355 & 2411 & 2223 & 2360 & 2457 & 2387 & 2017 & 1761 & 1749 \\
\hline $\mathrm{S}$ & 2521 & 2947 & 2637 & 2263 & 2005 & 1821 & 1860 & 2168 & 2432 & 2283 & 2009 & 2164 \\
\hline SW & 1993 & 2426 & 2256 & 2162 & 2082 & 2069 & 2063 & 2160 & 2065 & 1795 & 1494 & 1634 \\
\hline W & 1032 & 1405 & 1586 & 1839 & 1996 & 2170 & 2129 & 1930 & 1520 & 1138 & 879 & 860 \\
\hline NW & 495 & 676 & 915 & 1307 & 1528 & 1765 & 1668 & 1358 & 993 & 735 & 595 & 501 \\
\hline
\end{tabular}

Table 2. Climate data for the Kredarica (Slovenia) [30].

\begin{tabular}{|c|c|c|c|c|c|c|c|c|c|c|c|c|}
\hline Month & 1 & 2 & 3 & 4 & 5 & 6 & 7 & 8 & 9 & 10 & 11 & 12 \\
\hline \multicolumn{13}{|c|}{$T_{1}$-average temperature $\left[{ }^{\circ} \mathrm{C}\right], T_{2}$-average highest day temperature $\left[{ }^{\circ} \mathrm{C}\right]$} \\
\hline$T_{1}$ & -7.2 & -8.0 & -6.6 & -4.5 & 0.3 & 3.4 & 6.1 & 6.4 & 3.6 & 0.5 & -4.1 & -6.0 \\
\hline$T_{2}$ & -4.4 & -5.0 & -3.8 & -1.9 & 2.7 & 6.0 & 9.1 & 9.3 & 6.4 & 3.1 & -1.3 & -3.2 \\
\hline \multicolumn{13}{|c|}{$\begin{array}{l}\text { Energy density of incident solar radiation falling on } \\
\text { a vertically set pane during one month period measured in }\left[\mathrm{Wh} / \mathrm{m}^{2}\right]\end{array}$} \\
\hline $\mathbf{N}$ & 299 & 446 & 636 & 968 & 1186 & 1403 & 1314 & 1020 & 806 & 567 & 379 & 288 \\
\hline NE & 308 & 480 & 811 & 1337 & 1741 & 1895 & 1866 & 1507 & 1041 & 640 & 407 & 296 \\
\hline E & 566 & 908 & 1388 & 1915 & 2351 & 2387 & 2523 & 2208 & 1640 & 1017 & 661 & 514 \\
\hline SE & 1140 & 1656 & 1970 & 2213 & 2406 & 2315 & 2564 & 2485 & 2173 & 1563 & 1088 & 974 \\
\hline S & 1595 & 2284 & 2338 & 2194 & 2107 & 2000 & 2252 & 2386 & 2420 & 1928 & 1310 & 1246 \\
\hline SW & 1318 & 1962 & 2115 & 2156 & 2251 & 2291 & 2571 & 2467 & 2214 & 1631 & 1023 & 971 \\
\hline W & 698 & 1167 & 1529 & 1848 & 2151 & 2351 & 2581 & 2199 & 1684 & 1056 & 602 & 510 \\
\hline NW & 317 & 538 & 866 & 1299 & 1613 & 1868 & 1942 & 1513 & 1064 & 628 & 388 & 293 \\
\hline
\end{tabular}

Table 3. Climate data for Portorož (Slovenia) [30].

\begin{tabular}{|c|c|c|c|c|c|c|c|c|c|c|c|c|}
\hline Month & 1 & 2 & 3 & 4 & 5 & 6 & 7 & 8 & 9 & 10 & 11 & 12 \\
\hline \multicolumn{13}{|c|}{$T_{1}$-average temperature $\left[{ }^{\circ} \mathrm{C}\right], T_{2}$-average highest day temperature $\left[{ }^{\circ} \mathrm{C}\right]$} \\
\hline$T_{1}$ & 4.1 & 4.5 & 7.4 & 11.6 & 16.4 & 20.1 & 22.5 & 21.7 & 17.6 & 13.6 & 8.4 & 5.1 \\
\hline$T_{2}$ & 8.6 & 9.7 & 13.1 & 16.8 & 21.8 & 25.5 & 28.4 & 28.2 & 23.9 & 19.0 & 13.2 & 9.7 \\
\hline \multicolumn{13}{|c|}{$\begin{array}{l}\text { Energy density of incident solar radiation falling on } \\
\text { a vertically set pane during one month period measured in }\left[\mathrm{Wh} / \mathrm{m}^{2}\right]\end{array}$} \\
\hline $\mathbf{N}$ & 335 & 490 & 731 & 1094 & 1341 & 1589 & 1433 & 1193 & 910 & 664 & 430 & 312 \\
\hline NE & 344 & 523 & 884 & 1391 & 1804 & 1980 & 1872 & 1615 & 1133 & 741 & 450 & 318 \\
\hline E & 605 & 945 & 1458 & 1950 & 2427 & 2482 & 2512 & 2342 & 1740 & 1151 & 714 & 530 \\
\hline SE & 1220 & 1730 & 2098 & 2319 & 2554 & 2472 & 2596 & 2682 & 2319 & 1769 & 1185 & 1010 \\
\hline$S$ & 1847 & 2572 & 2683 & 2480 & 2373 & 2257 & 2388 & 2705 & 2728 & 2291 & 1505 & 1394 \\
\hline SW & 1639 & 2422 & 2678 & 2622 & 2700 & 2773 & 2917 & 3045 & 2693 & 2049 & 1239 & 1161 \\
\hline W & 926 & 1550 & 2044 & 2306 & 2661 & 2935 & 3036 & 2853 & 2126 & 1371 & 754 & 640 \\
\hline NW & 378 & 686 & 1133 & 1591 & 1989 & 2320 & 2292 & 1974 & 1306 & 775 & 454 & 323 \\
\hline
\end{tabular}




\subsection{Calculation of the Heat Transfer Coefficient}

The calculation of the heat transfer coefficient of glazing is explained in [31]. It depends on the number of glazing layers and can be calculated as follows:

$$
U=\frac{1}{R_{s e}+\sum_{i=1}^{N} R_{g i}+\sum_{j=1}^{M} \frac{d_{j}}{\lambda_{j}}+R_{s i}}
$$

where $R_{s i}$ is internal surface resistance, $R_{s e}=0.04 \mathrm{~m}^{2} \mathrm{~K} / \mathrm{W}$ is external surface resistance, $R_{g i}$ is the thermal resistance of the $i$ th gas-filled gap, $d_{j}$ is the thickness of the $j$ th glass pane, $\lambda_{j}$ is the thermal conductivity of the $j$ th glass pane, $N$ is the number of gas-filled gaps, and $M$ is the number of glass panes $(M=N+1)$. The main contribution to the total thermal resistance of the glazing comes from the thermal resistance of the gas-filled gap $R_{g}$ and the internal surface resistance $R_{s i}$, while the resistance of the glass panes is only a minor correction. The thermal resistance of a gas-filled gap $R_{g}$ combines the effects of thermal convection $\left(h_{c g}\right)$ within a gap, and the thermal radiation of the glass panes transmitted through the gap $\left(h_{r g}\right)$. Thermal convection depends mainly on the type of gas occupying the gap, while thermal radiation depends strongly on the emissivity of the glass panes enclosing the space gap for the part of the EM spectrum emitted by a black body at room temperature. The lower the emissivity of the glass panes, the higher the resistance and the lower the value of heat transfer coefficient:

$$
R_{g}=\frac{1}{h_{c g}+h_{r g}},
$$

where

$$
h_{r g}=\frac{4 \sigma T_{m}^{3}}{\frac{1}{\epsilon_{1}}+\frac{1}{\epsilon_{2}}-1}
$$

and

$$
h_{c g}=N_{u} \frac{\lambda}{d}, \quad N_{u}=A\left(\frac{9.81 d^{3} \rho^{2} \Delta T}{T_{m} \mu^{2}} \frac{\mu c}{\lambda}\right)^{n} .
$$

In the above equations, $A$ and $n$ are the constants that depend on the orientation of the glazing. For vertical orientation, $A=0.035$ and $n=0.38$. The constants $\rho, \mu, \lambda$ and $c$ denote the density, dynamic viscosity, thermal conductivity and specific heat capacity of the gas filling the gaps, respectively. The values for argon are given in Table 4 . The mean temperature in the gap is denoted by $T_{m}, \Delta T$ denotes the temperature difference between the glass panes enclosing the gap, $d$ denotes the distance between the glass panes enclosing the gap, and $\epsilon_{1}$ and $\epsilon_{2}$ denote the emissivity for low-frequency EM waves of the glass panes enclosing the gap. According to [31], for the calculation of the average heat transfer coefficient, the mean temperature between the gaps for the double and triple glazing should be set to $283 \mathrm{~K}$, while for the temperature difference between the panes in the $i$-th gap $15 \mathrm{~K} \cdot R_{g i} / \Sigma R_{g i}$ should be applied. The internal surface resistance $R_{s i}$ is calculated as $R_{s i}=1 /\left(h_{c i}+h_{r i}\right)$, where $h_{c i}=3.6 \mathrm{~W} / \mathrm{Km}^{2}$ and $h_{r i}=4.1 \epsilon / 0.837 \mathrm{~W} / \mathrm{Km}^{2}$, where $\epsilon$ is the emissivity of the glass pane facing the building interior.

Table 4. Values of physical constants for argon.

\begin{tabular}{ccccc}
\hline Temperature $\left[{ }^{\circ} \mathbf{C}\right]$ & $\boldsymbol{\rho} \times \mathbf{~} \mathbf{~ g} / \mathbf{m}^{3}$ & $\boldsymbol{\mu} \times \mathbf{1 0 ^ { - 5 }} \mathbf{~} \mathbf{k g} \mathbf{m s}$ & $\boldsymbol{\lambda} \times \mathbf{1 0 ^ { - 2 }} \mathbf{W} / \mathbf{m K}$ & $\boldsymbol{c} \times \mathbf{1 0 ^ { 3 }} \mathbf{J} / \mathbf{k g K}$ \\
\hline-10 & 1.826 & 2.038 & 1.584 & 0.519 \\
0 & 1.762 & 2.101 & 1.634 & 0.519 \\
10 & 1.699 & 2.164 & 1.684 & 0.519 \\
20 & 1.640 & 2.228 & 1.734 & 0.519 \\
\hline
\end{tabular}




\subsection{Calculation of Solar Transmittance}

The principles of deriving the total solar energy transmittance $g$ are explained in [22]. Incident solar radiation falling on a glazing is partially reflected, partially transmitted, and partially absorbed by the glazing (Figure 1 (left)). The absorbed solar radiation is re-radiated, partly to the inside of the building and partly to the outside. The solar gain represents the part of the heat flux density of the incident solar radiation that penetrates the building and is composed of the transmitted solar radiation $\left(\tau_{e f f} q_{s o l}\right)$ and part of the absorbed solar radiation emitted to interior $\left(\gamma_{i} q_{s o l}\right)$ :

$$
q_{s}=g q_{s o l}=\left(\tau_{e f f}+\gamma_{i}\right) q_{s o l}
$$
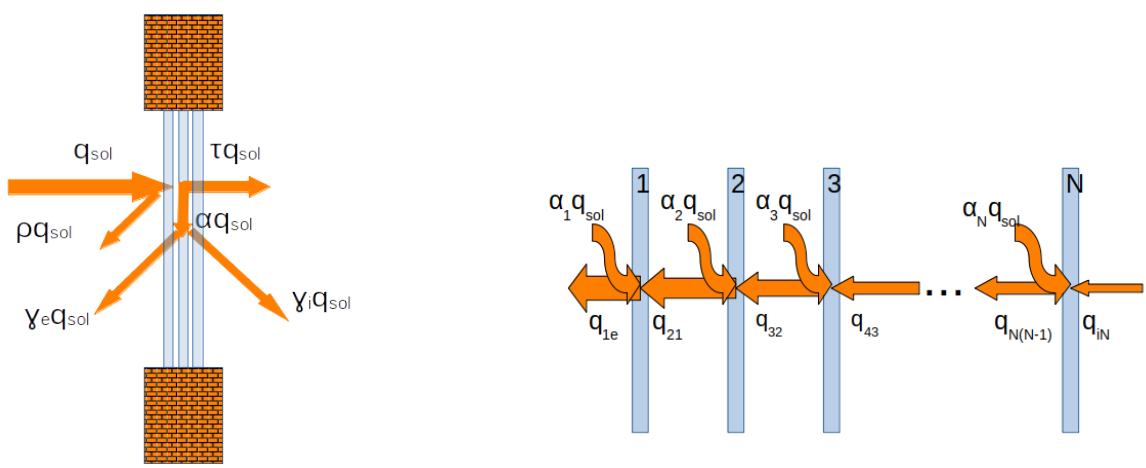

Figure 1. The contribution of incident solar radiation to solar heat gain.

The fraction of absorbed solar radiation emitted to the interior can be derived from the difference in the density of the heat flux with and without the contribution of absorbed solar radiation:

$$
\gamma_{i} q_{s o l}=q_{i N}-U\left(\theta_{i}-\theta_{e}\right)
$$

where $q_{i N}$ denotes the heat flux rate from inside the building and can be calculated by solving the system of equations (Figure 1 (right)):

$$
\begin{aligned}
& q_{21}+q_{1}=q_{1 e} \Rightarrow \frac{\theta_{2}-\theta_{1}}{R_{g 21}}+\alpha_{1 e} q_{s o l}=\frac{\theta_{1}-\theta_{e}}{R_{s e}}, \\
& q_{32}+q_{2}=q_{21} \Rightarrow \frac{\theta_{3}-\theta_{2}}{R_{g 32}}+\alpha_{2 e} q_{s o l}=\frac{\theta_{2}-\theta_{1}}{R_{g 21}}, \\
& q_{43}+q_{3}=q_{32} \Rightarrow \frac{\theta_{4}-\theta_{3}}{R_{g 43}}+\alpha_{3 e} q_{s o l}=\frac{\theta_{3}-\theta_{2}}{R_{g 32}}, \\
& q_{i N}+q_{N}=q_{N(N-1)} \Rightarrow \frac{\theta_{i}-\theta_{N}}{R_{s i}}+\alpha_{N e} q_{s o l}=\frac{\theta_{N}-\theta_{N-1}}{R_{g N(N-1)}} .
\end{aligned}
$$

In the above equations, $\alpha_{n e}$ denotes the effective absorption coefficient and $\theta_{n}$ denotes the temperature of the $n$-th glass pane. The thermal resistance of a gap between the $i$-th and the $j$-th pane $R_{g i j}$, internal surface resistance $R_{s i}$, and external surface resistance $R_{s e}$ are redefined to account for the thermal resistance of the glass panes. The equations can be written in a matrix form for a double glazing system:

$$
\left[\begin{array}{cc}
\frac{R_{g}}{R_{s e}}+1 & -1 \\
-1 & \frac{R_{s i}}{R_{g}}+1
\end{array}\right]\left[\begin{array}{l}
\theta_{1} \\
\theta_{2}
\end{array}\right]=\left[\begin{array}{c}
\alpha_{1 e} R_{g} q_{s o l}+\frac{R_{g}}{R_{s e}} \theta_{e} \\
\alpha_{2 e} R_{g} q_{s o l}+\frac{R_{g}}{R_{s i}} \theta_{i}
\end{array}\right],
$$


and for a triple glazing system:

$$
\left[\begin{array}{ccc}
\frac{R_{g 21}}{R_{s e}}+1 & -1 & 0 \\
-\frac{R_{g 32}}{R_{g 21}} & 1+\frac{R_{g 32}}{R_{g 21}} & -1 \\
0 & -1 & \frac{R_{s i}}{R_{g 32}}+1
\end{array}\right]\left[\begin{array}{c}
\theta_{1} \\
\theta_{2} \\
\theta_{3}
\end{array}\right]=\left[\begin{array}{c}
\alpha_{1 e} R_{g 21} q_{s o l}+\frac{R_{g 21}}{R_{s e}} \theta_{e} \\
\alpha_{2 e} R_{g 32} q_{s o l} \\
\alpha_{3 e} R_{32 g} q_{s o l}+\frac{R_{32 g}}{R_{s i}} \theta_{i}
\end{array}\right]
$$

Effective transmittance of multiple glazing $\tau_{e f f}$ also includes contribution from multiple reflections between glass panes (see Figure 2). For double glazing, it can be calculated by adding the geometrical series:

$$
\tau_{e 1 f f 2}=\tau_{1} \tau_{2}\left(1+\rho_{1}^{i} \rho_{2}^{e}+\left(\rho_{1}^{i} \rho_{2}^{e}\right)^{2}+\ldots\right)=\frac{\tau_{1} \tau_{2}}{1-\rho_{1}^{i} \rho_{2}^{e}},
$$

where $\tau_{i}$ denotes the transmittance of the $i$ - th glass pane, $\rho_{i}^{i}$ denotes the reflectance of the surface facing interior of the $i$-th glass pane, and $\rho_{i}^{e}$ denotes the reflectance of the surface facing the exterior of the $i$-th glass pane. The panes are numbered so that pane No. 1 faces the outside and pane No. 2 faces the inside of the building. Similarly, the effective reflectance of the double glazing, and the effective absorptance of the individual panes in the double glazing can be calculated as follows:

$$
\begin{gathered}
\rho_{e f f 12}^{e}=\rho_{1}^{e}+\frac{\tau_{1}^{2} \rho_{2}^{e}}{1-\rho_{1}^{i} \rho_{2}^{e}}, \quad \rho_{e f f 12}^{i}=\rho_{2}^{i}+\frac{\tau_{2}^{2} \rho_{1}^{i}}{1-\rho_{1}^{i} \rho_{2}^{e}}, \\
\alpha_{1 e f f}^{e}=\alpha_{1}^{e}+\frac{\tau_{1} \rho_{2}^{e} \alpha_{1}^{i}}{1-\rho_{1}^{i} \rho_{2}^{e}}, \quad \alpha_{2 e f f}^{e}=\frac{\tau_{1} \alpha_{2}^{e}}{1-\rho_{1}^{i} \rho_{2}^{e}} .
\end{gathered}
$$

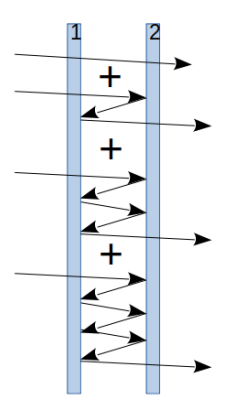

Figure 2. Contributions to solar transmittance due to reflections.

In the case of triple glazing effective transmittance, effective reflectance, and effective absorptance of individual panes can be written as:

$$
\begin{gathered}
\tau_{e f f 123}=\frac{\tau_{e f f 12} \tau_{3}}{1-\rho_{e f f 12}^{i} \rho_{3}^{e}}, \\
\rho_{e f f 123}^{e}=\rho_{e f f 12}^{e}+\frac{\tau_{e f f 12}^{2} \rho_{3}^{e}}{1-\rho_{e f f 12}^{i} \rho_{3}^{e}}, \quad \rho_{e f f 123}^{i}=\rho_{3}^{i}+\frac{\tau_{3}^{2} \rho_{e f f 12}^{i}}{1-\rho_{e f f 12}^{i} \rho_{3}^{e}}, \\
\alpha_{1 e f f 123}^{e}=\alpha_{1 e f f}+\frac{\tau_{1} \rho_{e f f 23}^{e} \alpha_{1}^{i}}{1-\rho_{1}^{i} \rho_{e f f 23}^{e}}, \quad \alpha_{3 e f f 123}^{e}=\frac{\tau_{e f f 12} \alpha_{3}^{e}}{1-\rho_{e f f 12}^{i} \rho_{3}^{e}}, \\
\alpha_{2 e f f 123}^{e}=\frac{\tau_{1} \alpha_{2}^{e}}{\left(1-\rho_{1}^{i} \rho_{2}^{e}\right)\left(1-\rho_{1}^{i} \rho_{3}^{e} \tau_{2}^{2}\right)}+\frac{\tau_{1} \tau_{2} \rho_{3}^{e} \alpha_{2}^{i}}{\left(1-\rho_{2}^{i} \rho_{3}^{e}\right)\left(1-\rho_{1}^{i} \rho_{3}^{e} \tau_{2}^{2}\right)},
\end{gathered}
$$


where the subscript ef $f i j$ denotes the effective transmittance or reflectance of an independent double-glazing system consisting of the $i$ th and $j$ th glass panes. The glass panes are numbered so that pane No. 1 faces outward, pane No. 3 faces inward, and pane No. 2 is in the centre. The Equations (15) and (16) are derived from the Equation (14) by iteration, while the Equation (17) is evaluated manually by adding the geometric series of all possible reflections between the glass panes of a triple glazing.

\section{Properties of Glass Panes Available on the EU Market}

In this section an overview of the glass panes available on the European market and their optical properties is given. For this purpose, the extensive database of glass panes from the open source program Windows [23] has been used. As the case study is conducted for the European region, only the largest manufacturers present in the European market were selected from the database [32]. This was done to ensure that there are no problems with the supply. In addition, only glass panes with a thickness between $3 \mathrm{~mm}$ and $12 \mathrm{~mm}$ were considered, as thicker or thinner glass panes are not usually used for window glazing. The reduced database still contains over 1000 different types of glass panes.

The aim of this section is to highlight the properties of glass panes, their correlations and their influence on heating and cooling requirements. First, the pane properties are analyzed individually, and their influence on heat transfer coefficient and total solar transmittance is discussed. Second, correlations that have been identified as important and that can have a significant impact on heat transfer coefficient and total solar transmittance are discussed.

The following parameters from the reduced database are analyzed: thermal conductivity, emissivity for IR spectrum, transmittance for solar spectrum, reflectance for solar spectrum and glass thickness. Figure 3 shows the distribution of glass panes according to the values of the above parameters. The glass panes were first sorted according to the studied parameter and then plotted in a graph.

The distribution by glass thickness is shown in Figure 3, first column, first row. From the figure it can be concluded that we can choose from glass panes in all thickness categories from $3 \mathrm{~mm}$ to $12 \mathrm{~mm}$. As expected, glass panes with thickness less than $8 \mathrm{~mm}$ are the most common, as they are more frequently used in the window industry compared to thicker glass panes. No significant relationship was found between glass thickness and other parameters. Moreover, glass thickness has negligible influence on heat transfer coefficient and total solar transmittance.

The distribution of glass panes by thermal conductivity is shown in Figure 3, first row, second column. Most glass types have a thermal conductivity of $1 \mathrm{~W} / \mathrm{mK}$, although glass with lower thermal conductivity (down to $0.5 \mathrm{~W} / \mathrm{mK}$ ) can also be found. Similar to glass thickness, thermal conductivity has no effect on total solar transmittance and solar gain, and its influence on heat transfer coefficient is insignificant.

The distribution of the emissivity of glass panes for the infrared spectrum is shown graphically in the second row in Figure 3. The emissivity of glass panes on lower emissivity side is given in the first column, while the emissivity of glass panes on higher emissivity side is given in the second column. A clear distinction can be made between glass panes with and without low-emissivity coatings. Classic glass has an emissivity of 0.84 , while with the low-emissivity coating the IR emissivity of the glass panes can reach values from 0.013 to 0.2 on side with the coating. The figures also confirm that almost all glass panes have low-emissivity coating on one side only. Since the low-emissivity coating is sensitive to mechanical injury, glass panes in double or triple glazing should be positioned so that the low-emissivity coating faces the gap. 


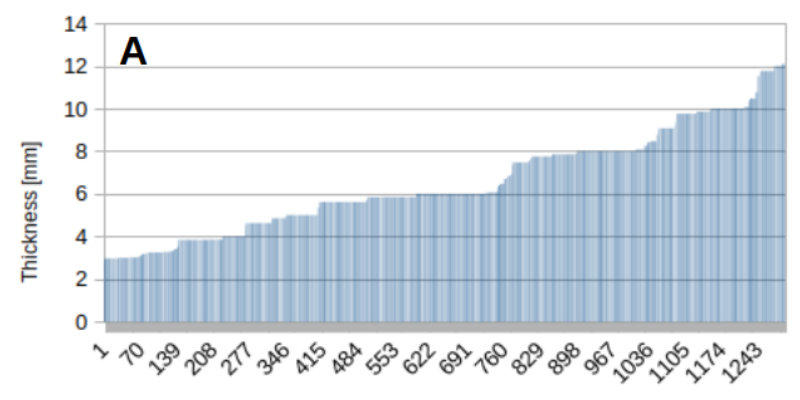

Pane serial number

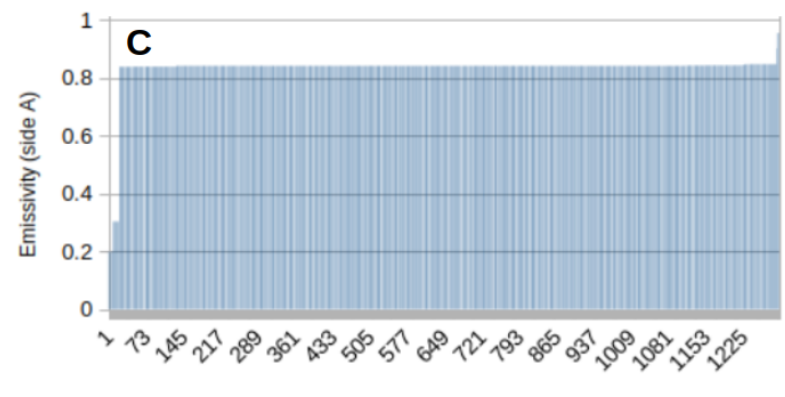

Pane serial number

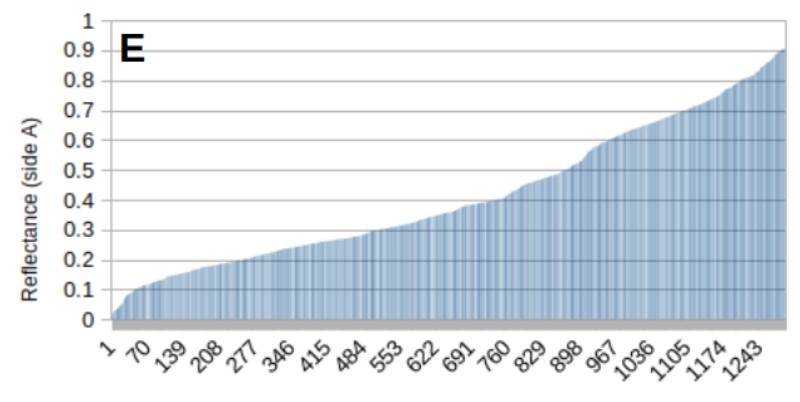

Pane serial number
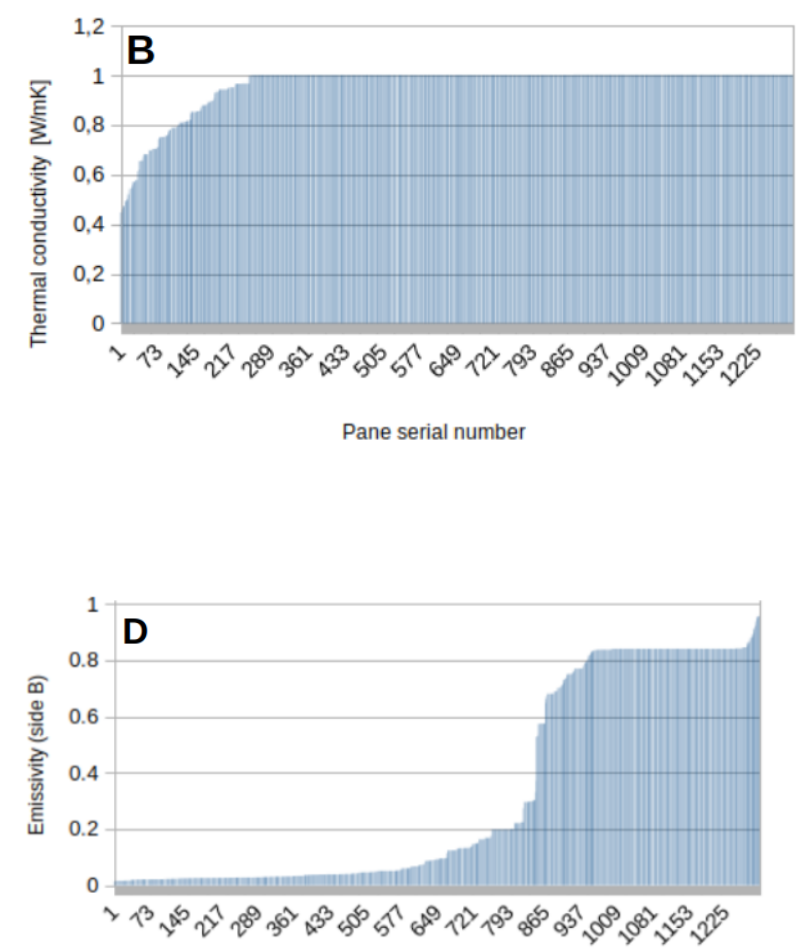

Pane serial number

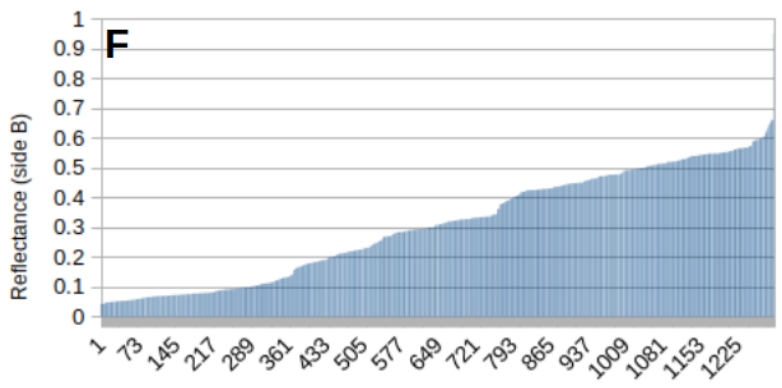

Pane serial number

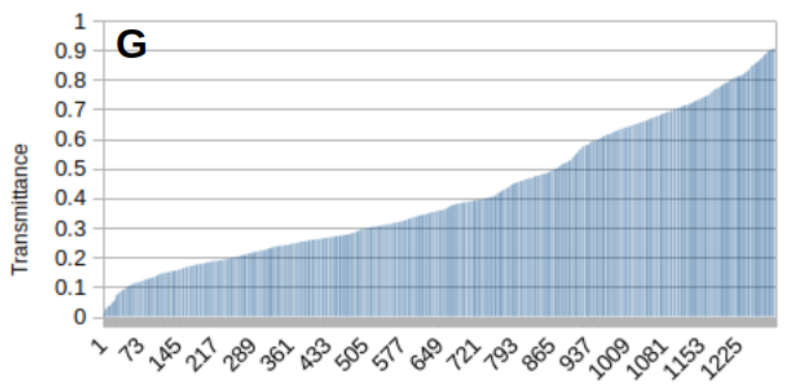

Pane serial number

Figure 3. Distribution of optical properties of glass panes available on European market: (A) thickness, (B) conductivity, (C) emissivity (side A), (D) emissivity (side B), (E) reflectance (side A), (F) reflectance (side B), (G) transmittance. The panes are sorted by studied parameter and than presented in a graph. Each vertical line presents one pane. 
Emissivity has an important influence on heat transfer coefficient. A low-emissivity pane will significantly reduce heat loss through a gap. In fact, when glass panes with no emissivity enclose the gap, radiation is the main cause of heat loss. Radiant heat coefficient $h_{r g}$ in Equation (5) has a value of about $3.7 \mathrm{~W} / \mathrm{Km}^{2}$, while the convective heat coefficient $h_{c g}$ has approximately three times lower value. On the other hand, if one of the panes enclosing the gap has emissivity of 0.03 , the radiative heat coefficient drops to $0.15 \mathrm{~W} / \mathrm{Km}^{2}$. However, two low emissivity panes do not reduce the heat loss much further. Convection heat transfer coefficient becomes more significant and further reducing the heat coefficient from $0.15 \mathrm{~W} / \mathrm{Km}^{2}$ to $0.07 \mathrm{~W} / \mathrm{Km}^{2}$ has a negligible effect on the heat transfer coefficient. The emissivity has no direct effect on total solar transmittance, but can affect it indirectly trough correlations with the transmittance and reflectance. Therefore, the correlations between emissivity, transmittance and reflectance need to be investigated.

The distribution of transmittance for solar spectrum of glass panes is shown in Figure 3, last row. The transmittance of glass panes can reach values from $0 \%$ to $91 \%$. The transmittance of glass in the solar spectrum is highly correlated with the transmittance of glass in the visual spectrum, as shown in Figure 4, first column, first row. Transmittance for solar radiation plays an important role in determining total solar transmittance and solar gain. The correlation between transmittance and emissivity of glass panes is shown in Figure 4, first column, second row. Panes with and without low-emissivity coating can be clearly distinguished from each other. The figure also shows that glass panes without emissivity achieve higher transmittance values than glass panes with a low-emissivity coating. Therefore, the combination of glass panes with a low-emissivity coating and clear glass panes without a low-emissivity coating can achieve better results than glazing with only low-emissivity glass panes. Figure 4, first column, third row, shows the correlation with transmittance and emissivity for coatings with emissivity from 0.03 to 0.02 . The figure shows that the glass panes with the lowest emissivity also have lower solar transmittance. Therefore, a glass pane with a slightly higher emissivity, but also a higher transmittance, could cause a lower heat demand in cold climates than the glass pane with the lowest emissivity value and consequently the lowest heat transfer coefficient value. A series of linear functions describing the correlation between emissivity and the upper limit for transmittance for glass panes with low emissivity from 0.03 to 0.2 can be obtained:

$$
\tau= \begin{cases}7.7794 \varepsilon+0.3344 & \varepsilon \in(0.013,0.047) \\ 1.0256 \varepsilon+0.6518 & \varepsilon \in(0.047,0.086) \\ -2.963 \varepsilon+0.9948 & \varepsilon \in(0.086,0.14) \\ 3.6660 \varepsilon+0.0666 & \varepsilon \in(0.14,0.2)\end{cases}
$$

The distribution of glass panes by reflectance is shown in Figures 3, third row. The reflectance of glass panes on a side with lower emissivity (low-emissivity coating, if present) is shown in the first column, while the reflectance of glass panes on a side with higher emissivity is shown in the second column. The figures show that the reflectance of glass panes on a side without a low-emissivity coating varies between $4 \%$ and $63 \%$, and is slightly higher (up to $66 \%$ ) on a side with a low-emissivity coating. Reflectance affects total solar transmittance, although to a lesser extent than transmittance. A higher reflectance on an outward-facing side of the panes results in a lower total solar transmittance. The correlation between reflectance and emissivity is shown in the diagrams in Figure 4, second column. The diagrams show that the emissivity on a coated side correlates with the reflectance. That is, panes with lower values of emissivity have higher values of reflectance. 

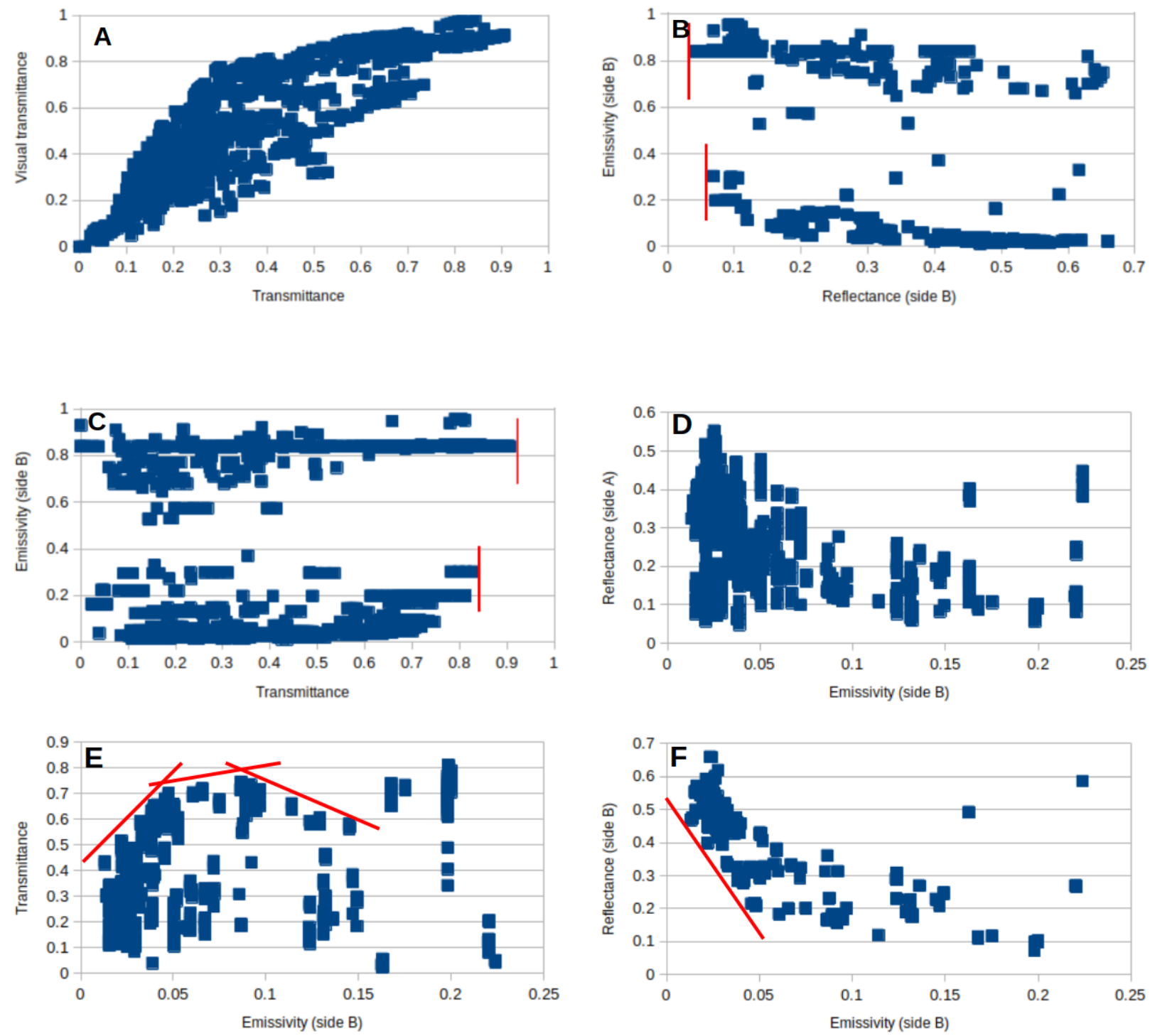

Figure 4. Correlation between optical properties of glass panes availabe on European market: (A) transmittance for solar spectrum (horizontal axis) vs visual transmittance (vertical axis), (B) reflectance on a side with low-emissivity coating (horizontal axis) vs emissivity on a side with low-emissivity coating (vertical axis), (C) transmittance (horizontal axis) vs emissivity on a side with low-emissivity coating (vertical axis), (D) emissivity on a side with low-emissivity coating (horizontal axis) vs reflectance on a side without low-emissivity coating (vertical axis), (E) emissivity on a side with low-emissivity coating (horizontal axis) vs transmittance (vertical axis), (F) emissivity on a side with low-emissivity coating (horizontal axis) vs reflectance on a side with low-emissivity coating (vertical axis).

\section{Results and Discussion}

The average monthly maximum daily temperatures at Krederica do not exceed $10{ }^{\circ} \mathrm{C}$ (see Table 2). According to meteorological data, glazing with low heat transfer coefficient and high solar transmittance should be used. Glazing with the right combination of clear glass with and/or without low-emissivity coating is preferred. Therefore, the following settings are tested for the double glazing: (a) both panes with the highest transmittance (clear glass without low-emissivity coating); (b) inner pane with low-emissivity coating, outer pane clear glass without low-emissivity coating; (c) outer pane with low-emissivity coating, inner pane clear glass without low-emissivity coating; (d) both panes with lowemissivity coating. A similar setting is tested for triple glazing: (a) all panes with clear glass 
without low-emissivity coating; (b) inner pane with low-emissivity coating, other panes of clear glass; (c) outer pane with low-emissivity coating, other panes of clear glass; (d) middle pane with low-emissivity coating, other panes of clear glass; (e) inner pane of clear glass, other panes with low-emissivity coating; (f) outer pane of clear glass, other panes with low-emissivity coating; $(\mathrm{g})$ central pane of clear glass, other panes with low-emissivity coating; (h) all panes with low-emissivity coating. For the clear glass, the transmittance is set to 0.91 and the emissivity is set to 0.84 . For glass with low-emissivity coatings, the emissivity is varied from 0.013 to 0.2 , and the transmittance is calculated from the emissivity according to the relationships in Equation (18). It is assumed that the effects of reflectance are less important than the effects of transmittance and emissivity. Therefore, the results with the lowest and the highest possible reflectance are presented.

In Figure 5, the heating demand for double glazing on a building with low solar gains in Kredarica is presented for different orientations. Since the average daily temperatures and the highest average daily temperatures do not exceed $20^{\circ}$, there is no cooling demand and the results can be applied to both low and high impedance buildings. As it can be seen from Figure 5, the use of at least one pane with a low-emissivity coating significantly reduces the heat demand. Moreover, the lowest heat demand is obtained with glazing with clear glass for the inner pane and low-emissivity glass for the outer pane with the lowest possible emissivity value. The position of the low-emissivity glass pane (as inner or outer pane) has no influence on the heat transfer coefficient, because the low-emissivity coating is applied only on the side facing the gap. The positioning of the pane also has no effect on the effective transmittance, but it does on the effective reflectance. Since the low-emissivity pane has a slightly higher reflectance on the side with the low-emissivity coating, it reflects more heat when it is facing outward (as an inner pane) than when it is facing inward (as an outer pane). Because of this difference, solar radiation is higher for low-emissivity glazing positioned as an exterior pane. When the emissivity value is higher than 0.05 , the heat demand is lower for low emissivity glazing positioned as an interior pane when oriented northeast to northwest, while for other orientations both positions give similar results. When the emissivity is higher than 0.150 , a lower heat demand is obtained for the glass with the low-emissivity as the inner pane. Similar results are obtained when the glazing is installed in a building with high solar gains. The only difference is that there is present a small cooling demand for glazing with clear glass for the inner pane and low-emissivity glass for the outer pane with low values of emissivity. The sum of heating and cooling demand for double glazing on a building with high solar gains at Kredarica for different orientations is shown in Figure 6. Similar to a building with low solar gains, glazing with inner clear glass and outer pane with low-emissivity coating gives the lowest value for the sum of heating and cooling demand.

The heating demand for triple glazing on a building with low solar gains at Kredarica is shown in Figure 7. The lowest heating demand can be obtained with glazing with either three or two low emissivity glass panes with the emissivity value of 0.05 . Nevertheless, for the building with high solar gains and without shading (see Figure 8), overheating effects can be observed, which are particularly noticeable for glazing with low emissivity glass panes between 0.05 and 0.1 . Thus, if shading is not used, the sum of heating and cooling requirements may be lower for glazing with the low-emissivity pane with slightly lower emissivity value of 0.025 . However, this overheating can be regulated by using shading elements with a shading factor of 0.2 (see Figure 9).

Figures 10-12 and 13-15 show the heating demand and the sum of heating and cooling demand, for double and triple glazing for different orientations on buildings with very high impedance in Maribor. Meteorological data for Maribor (see Table 1) show that average temperatures are much higher compared to average temperatures at Kredarica. However, the heating season is still predominant. Average daily temperatures in Maribor also do not exceed $20^{\circ} \mathrm{C}$, but average daily maximum temperatures in June, July and August exceed $24.5^{\circ} \mathrm{C}$. Buildings with very low impedance (time constant less than $8 \mathrm{~h}$ ) must be cooled during the hottest periods of the day. In addition, so-called heat waves are 
becoming more common, with daily maximum temperatures exceeding $30^{\circ} \mathrm{C}$ for several days. Even buildings with moderate impedance must be cooled during these heat waves. Therefore, it is expected that low and moderate impedance buildings will have higher cooling requirements than predicted by the model, which best describes high impedance buildings. The results for glazing performance in Maribor are similar to those in Kredarica. For double glazing on a building with low solar gains, glazing with an outer pane of emissivity of 0.003 and an inner pane of clear glass gives the lowest sum of cooling and heating demand. Similar results are obtained for double glazing on a building with high solar gains and shading elements during the cooling period with a shading factor of 0.2 . Nevertheless, if no shading is applied, it is better to use a pane with the lowest emissivity as the inner pane and clear glass as the outer pane (see Figure 14). For triple glazing on a building with high solar gains and without shading, overheating is much more evident for glazing with glass panes with a low-emissivity coating with emissivity values between 0.05 and 0.1 . For east, southeast, south and southwest orientations, these overheating effects are so strong that these panes have the highest sum of heating and cooling demand. Although overheating can be regulated by using shading elements with a shading factor of 0.2 during the cooling season, it is better to use panes with a slightly lower emissivity of 0.025 , which perform well in buildings with both low and high solar gains.

Portorož has higher monthly average temperatures than Maribor, but similar to Maribor, the heating season is predominant. The heating demand or the sum of heating and cooling demand for Portorož is shown in Figures 16-18 and 19-21. Similar effects can be observed as in the case of Maribor, although on a larger scale. The only significant difference between Maribor and Portorož is that for double glazing on a building with high solar gains and no shading, glazing with an outer pane of clear glass and an inner pane with low-emissivity pane with emissivity value of about 0.03 achieves the lowest sum of heating and cooling demand (for Maribor, a low-emissivity pane with ten times lower value of emissivity is preferable). 

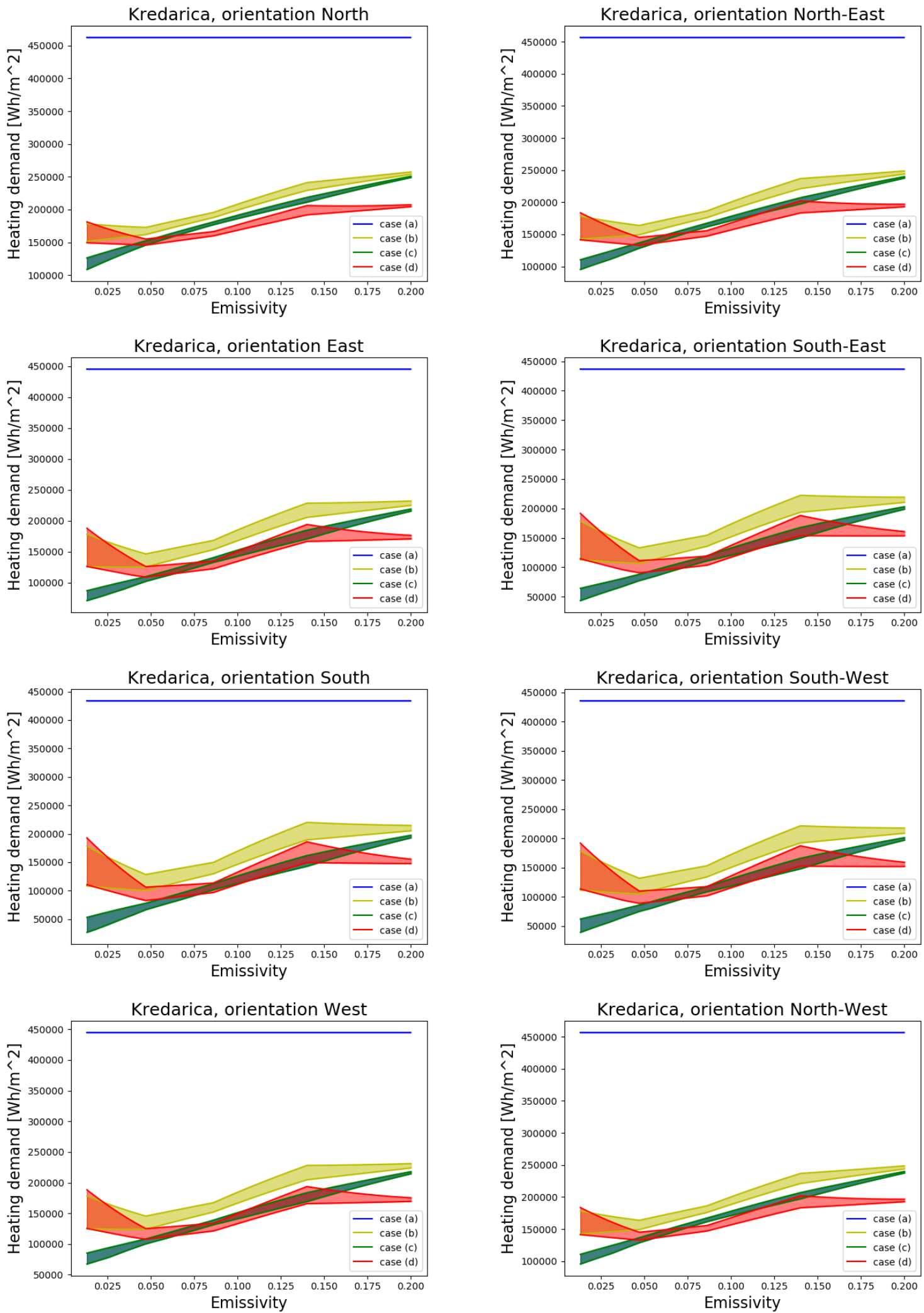

Figure 5. Annual heat loss per square meter of vertically set double glazing system on object located at Kredarica for high impedance building with low solar gains (badly insulated or/and windows with small ratio of window area): (a) both panes with highest transmittance (clear glass without low emissivity coating); (b) internal pane with low emissivity coating, external pane clear glass without low emissivity coating; (c) external pane with low emissivity coating, internal pane clear glass without low emissivity coating; (d) both panes with low emissivity coating. As in case (a) there is no low-emissivity pane, the glazing has fixed emissivity and therefore the results do not vary with the emissivity. Different cases include low-emissivity glass with different values of reflectance. 

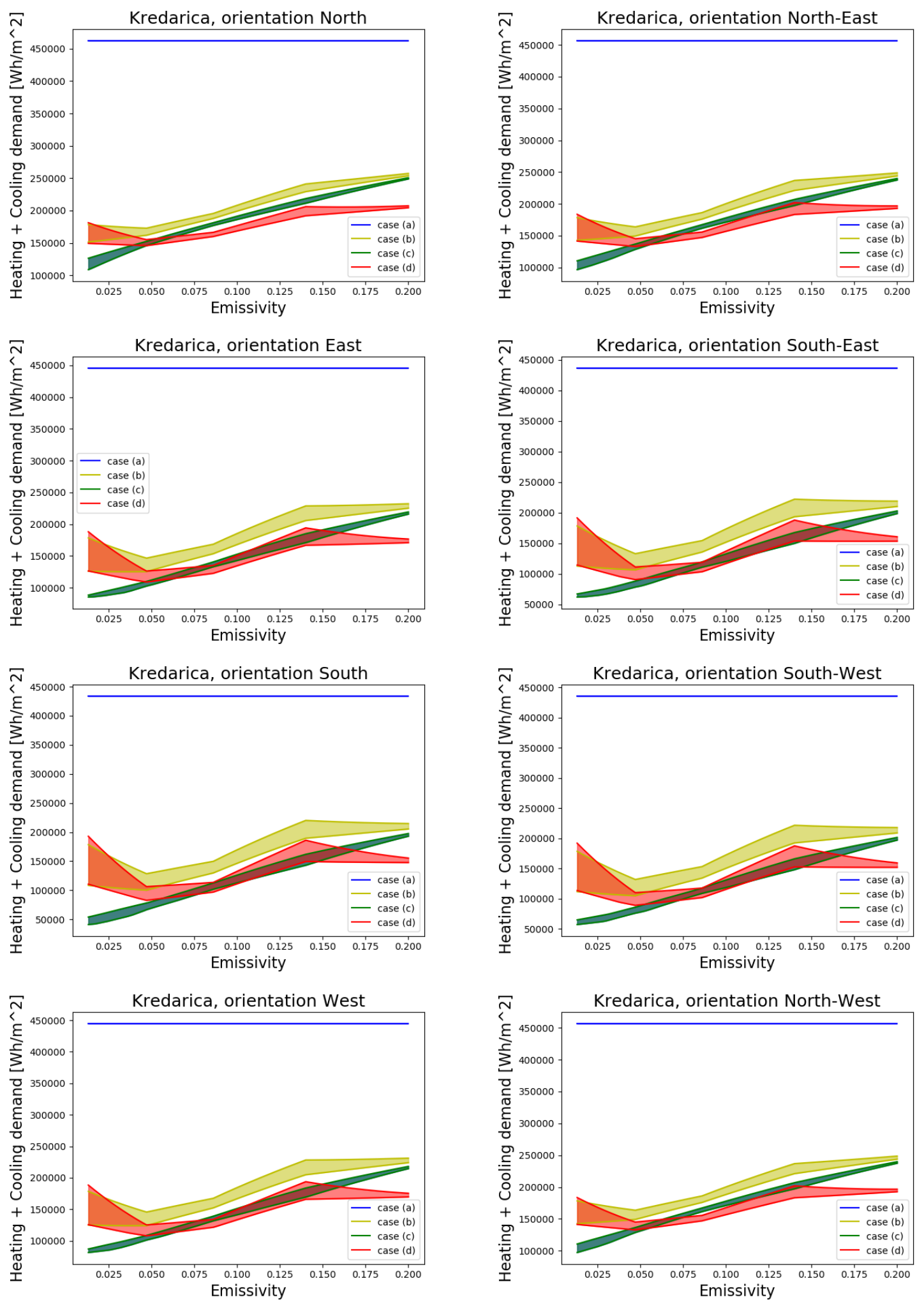

Figure 6. Annual heat loss per square meter of vertically set double glazing system on object located at Kredarica for high impedance building with high solar gains (well insulated or/and windows with large ratio of window area without shading during cooling season): (a) both panes with highest transmittance (clear glass without low emissivity coating); (b) internal pane with low emissivity coating, external pane clear glass without low emissivity coating; (c) external pane with low emissivity coating, internal pane clear glass without low emissivity coating; (d) both panes with low emissivity coating. As in case (a) there is no low-emissivity pane, the glazing has fixed emissivity and therefore the results do not vary with the emissivity. Different cases include low-emissivity glass with different values of reflectance. 

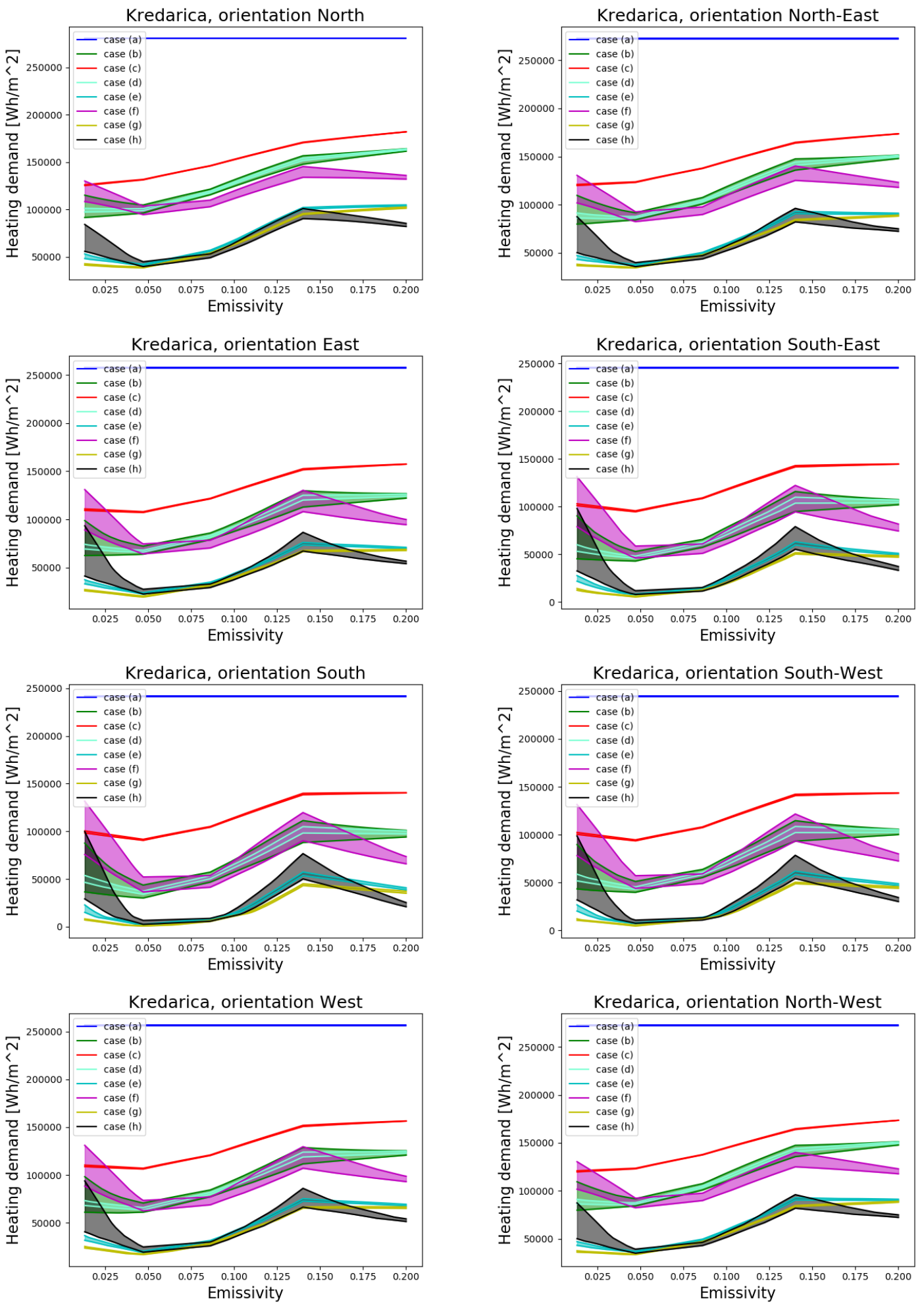

Figure 7. Annual heat loss per square meter of vertically set triple glazing system on object located at Kredarica for high impedance building with low solar gains (badly insulated or/and windows with small ratio of window area): (a) all panes with clear glass without low emissivity coating; (b) inner pane with low emissivity coating, other panes clear glass; (c) external pane with low emissivity coating, other panes clear glass; (d) middle pane with low emissivity coating, other panes clear glass; (e) inner pane clear glass, other panes with low emissivity coating; (f) external pane clear glass, other panes with low emissivity coating; (g) middle pane with clear glass, other panes with low emissivity coating; (h) all panes with low emissivity coating. As in case (a) there is no low-emissivity pane, the glazing has fixed emissivity and therefore the results do not vary with the emissivity. Different cases include low-emissivity glass with different values of reflectance. 

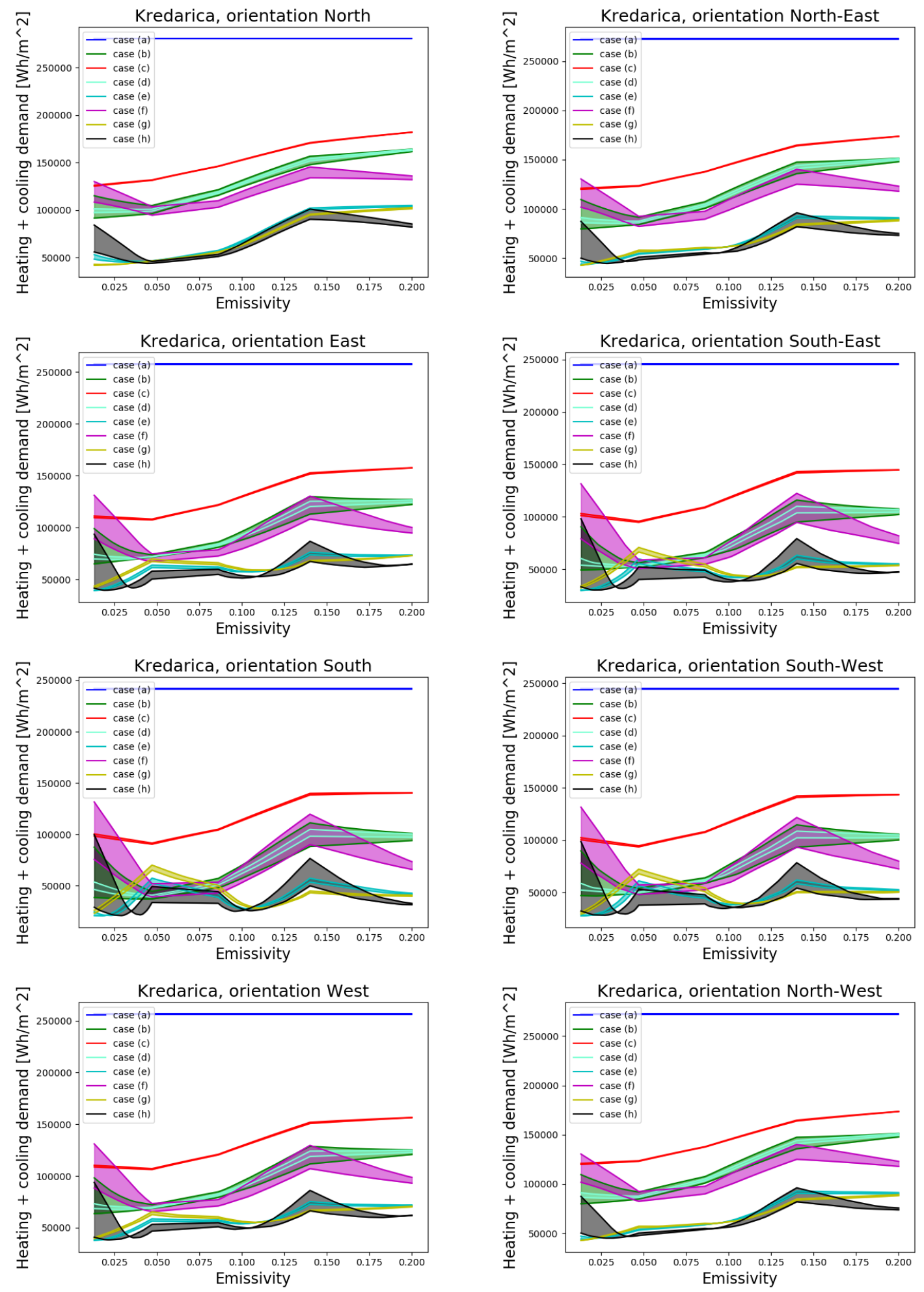

Figure 8. Annual heat loss per square meter of vertically set triple glazing system on object located at Kredarica for high impedance building with high solar gains (well insulated or/and windows with large ratio of window area without shading during cooling season): (a) all panes with clear glass without low emissivity coating; (b) inner pane with low emissivity coating, other panes clear glass; (c) external pane with low emissivity coating, other panes clear glass; (d) middle pane with low emissivity coating, other panes clear glass; (e) inner pane clear glass, other panes with low emissivity coating; (f) external pane clear glass, other panes with low emissivity coating; (g) middle pane with clear glass, other panes with low emissivity coating; (h) all panes with low emissivity coating. As in case (a) there is no low-emissivity pane, the glazing has fixed emissivity and therefore the results do not vary with the emissivity. Different cases include low-emissivity glass with different values of reflectance. 

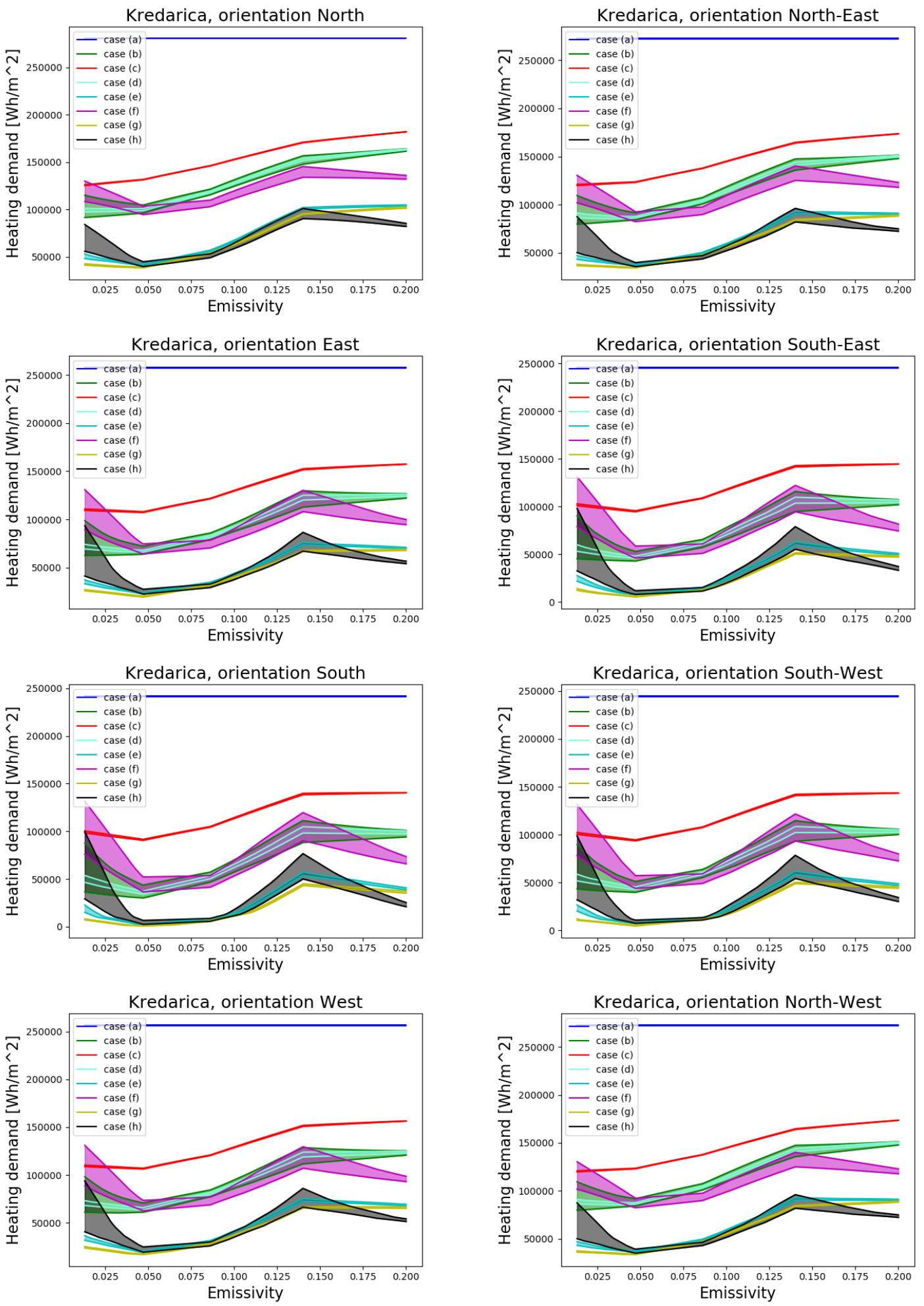

Figure 9. Annual heat loss per square meter of vertically set triple glazing system on object located at Kredarica for high impedance building with high solar gains (well insulated or/and windows with large ratio of window area with shading factor 0.2 during cooling season): (a) all panes with clear glass without low emissivity coating; (b) inner pane with low emissivity coating, other panes clear glass; (c) external pane with low emissivity coating, other panes clear glass; (d) middle pane with low emissivity coating, other panes clear glass; (e) inner pane clear glass, other panes with low emissivity coating; (f) external pane clear glass, other panes with low emissivity coating; (g) middle pane with clear glass, other panes with low emissivity coating; (h) all panes with low emissivity coating. As in case (a) there is no low-emissivity pane, the glazing has fixed emissivity and therefore the results do not vary with the emissivity. Different cases include low-emissivity glass with different values of reflectance. 

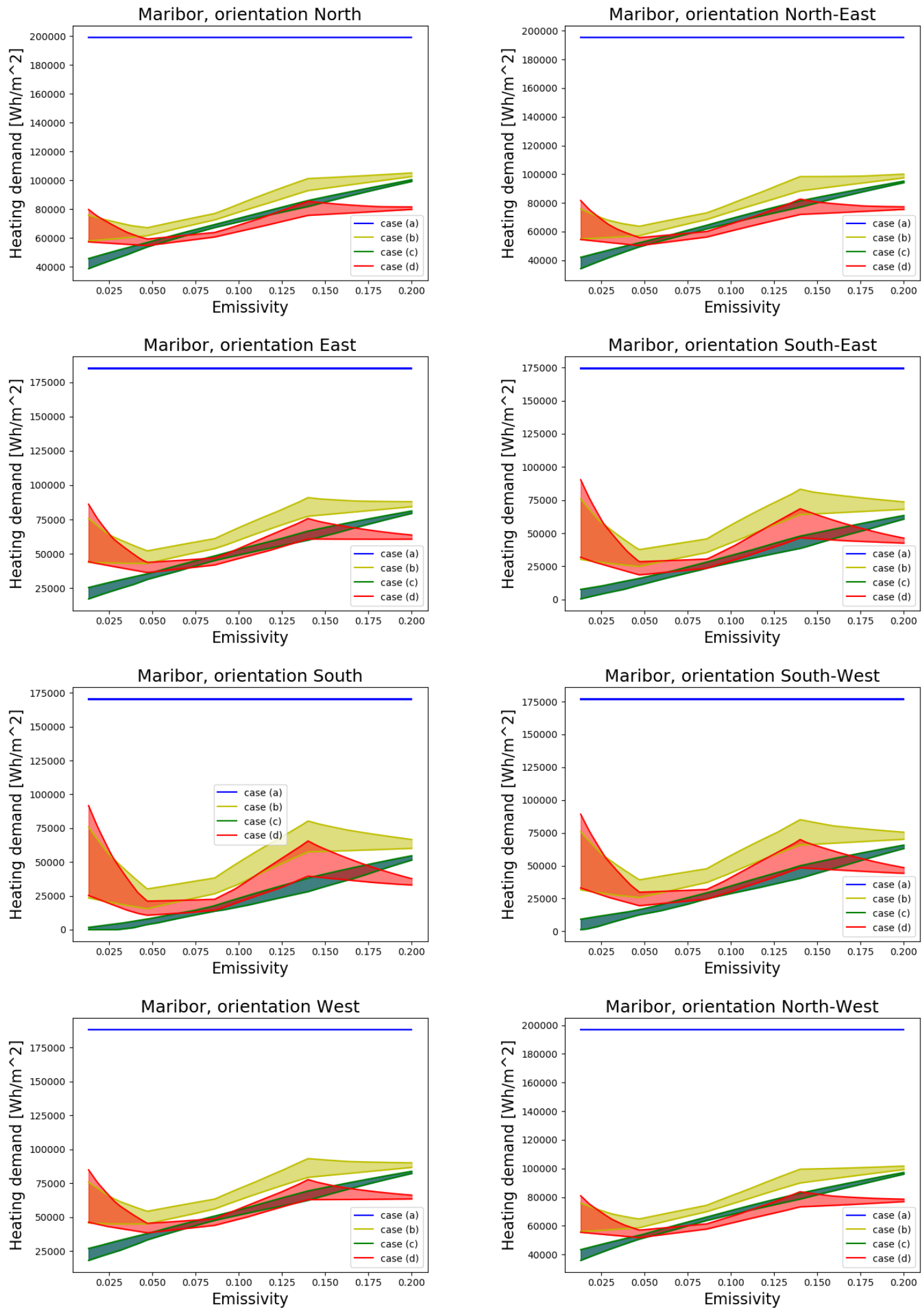

Figure 10. Annual heat loss per square meter of vertically set double glazing system on object located at Maribor for high impedance building with low solar gains (badly insulated or/and windows with small ratio of window area): (a) both panes with highest transmittance (clear glass without low emissivity coating); (b) internal pane with low emissivity coating, external pane clear glass without low emissivity coating; (c) external pane with low emissivity coating, internal pane clear glass without low emissivity coating; (d) both panes with low emissivity coating. As in case (a) there is no low-emissivity pane, the glazing has fixed emissivity and therefore the results do not vary with the emissivity. Different cases include low-emissivity glass with different values of reflectance. 

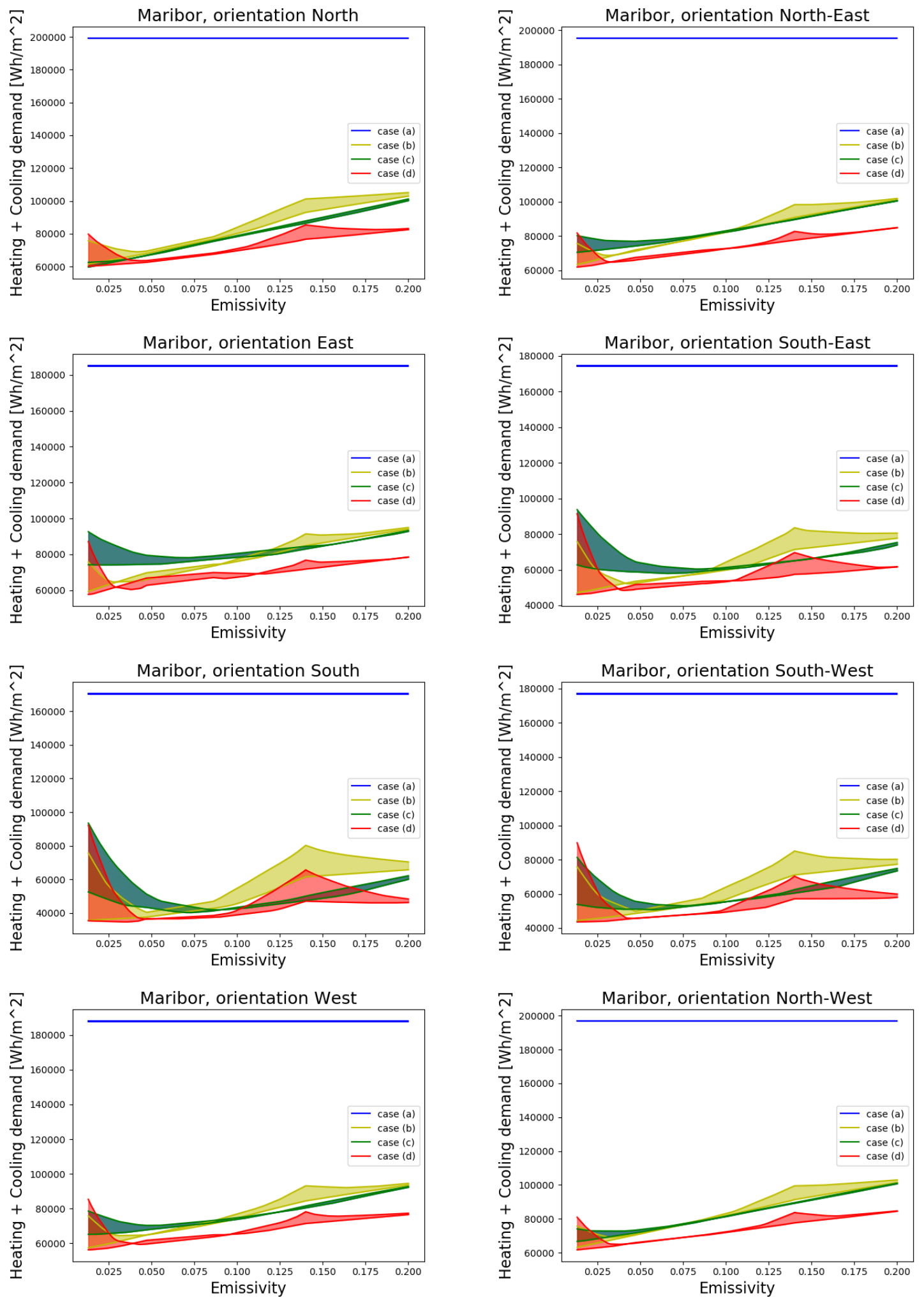

Figure 11. Annual heat loss per square meter of vertically set double glazing system on object located at Kredarica for high impedance building with high solar gains (well insulated or/and windows with large ratio of window area without shading during cooling season): (a) both panes with highest transmittance (clear glass without low emissivity coating); (b) internal pane with low emissivity coating, external pane clear glass without low emissivity coating; (c) external pane with low emissivity coating, internal pane clear glass without low emissivity coating; (d) both panes with low emissivity coating. As in case (a) there is no low-emissivity pane, the glazing has fixed emissivity and therefore the results do not vary with the emissivity. Different cases include low-emissivity glass with different values of reflectance. 

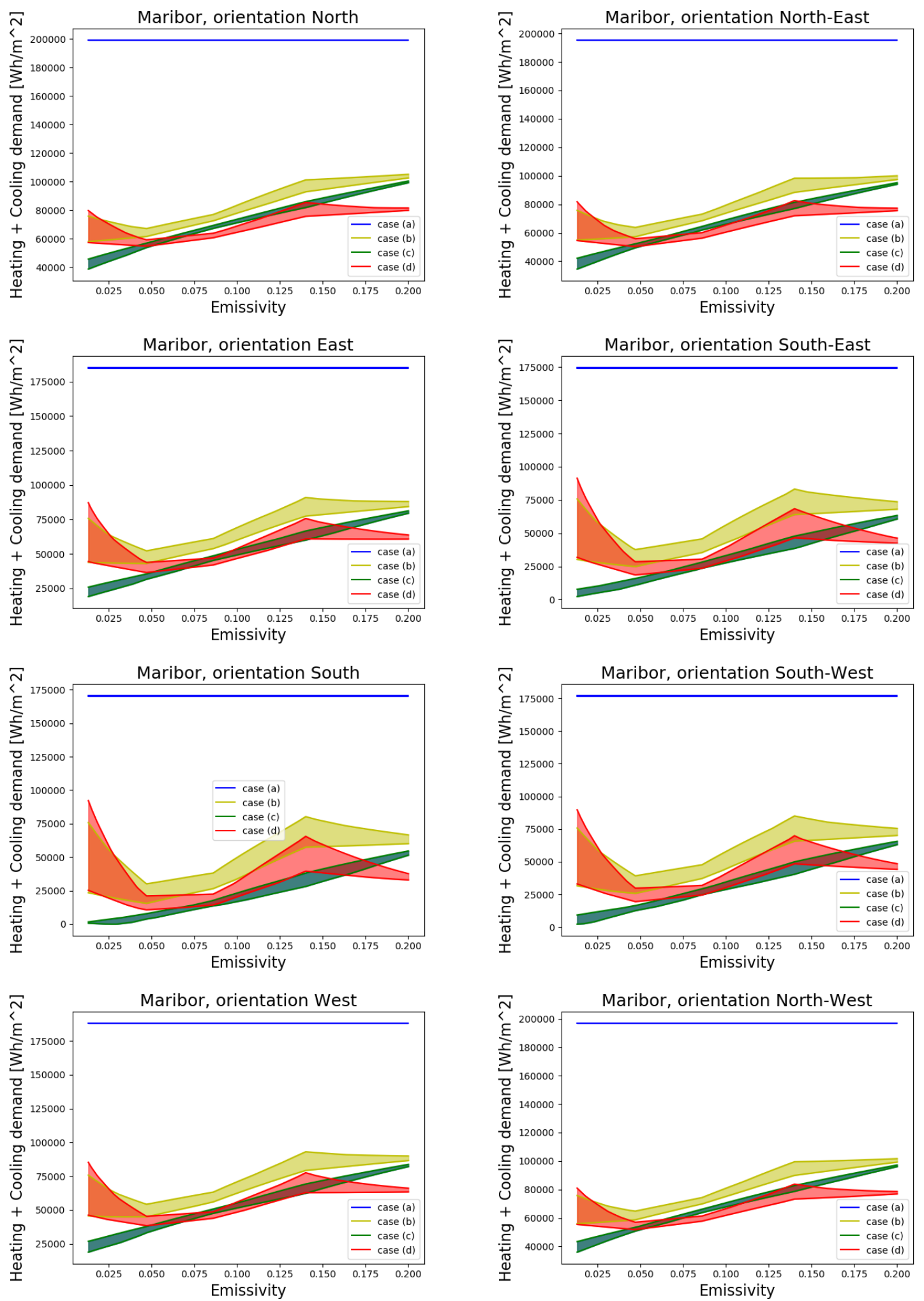

Figure 12. Annual heat loss per square meter of vertically set double glazing system on object located at Kredarica for high impedance building with high solar gains (well insulated or/and windows with large ratio of window area with shading factor 0.2 during cooling season): (a) both panes with highest transmittance (clear glass without low emissivity coating); (b) internal pane with low emissivity coating, external pane clear glass without low emissivity coating; (c) external pane with low emissivity coating, internal pane clear glass without low emissivity coating; (d) both panes with low emissivity coating. As in case (a) there is no low-emissivity pane, the glazing has fixed emissivity and therefore the results do not vary with the emissivity. Different cases include low-emissivity glass with different values of reflectance. 

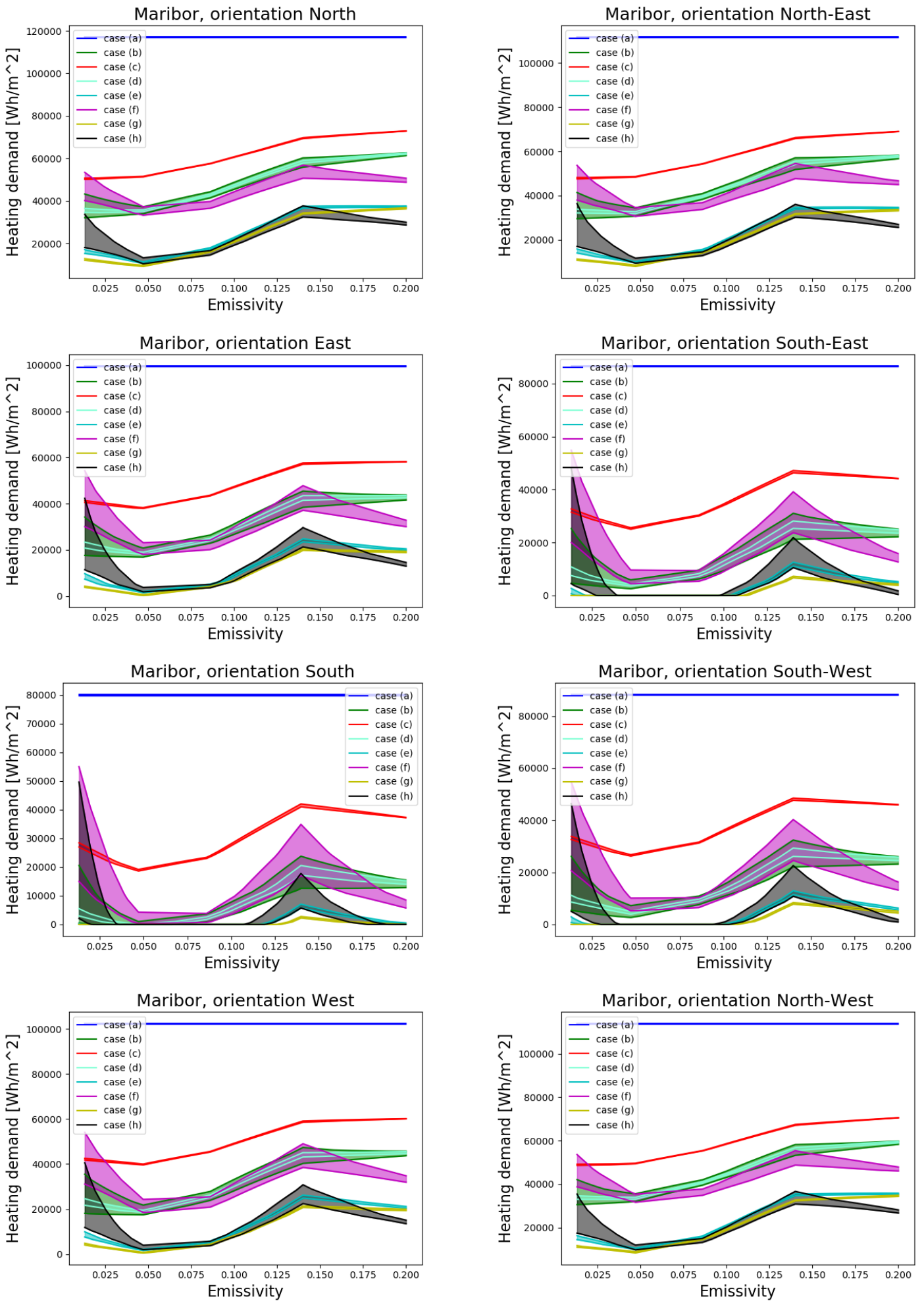

Figure 13. Annual heat loss per square meter of vertically set triple glazing system on object located at Maribor for high impedance building with low solar gains (badly insulated or/and windows with small ratio of window area): (a) all panes with clear glass without low emissivity coating; (b) inner pane with low emissivity coating, other panes clear glass; (c) external pane with low emissivity coating, other panes clear glass; (d) middle pane with low emissivity coating, other panes clear glass; (e) inner pane clear glass, other panes with low emissivity coating; (f) external pane clear glass, other panes with low emissivity coating; (g) middle pane with clear glass, other panes with low emissivity coating; (h) all panes with low emissivity coating. As in case (a) there is no low-emissivity pane, the glazing has fixed emissivity and therefore the results do not vary with the emissivity. Different cases include low-emissivity glass with different values of reflectance. 

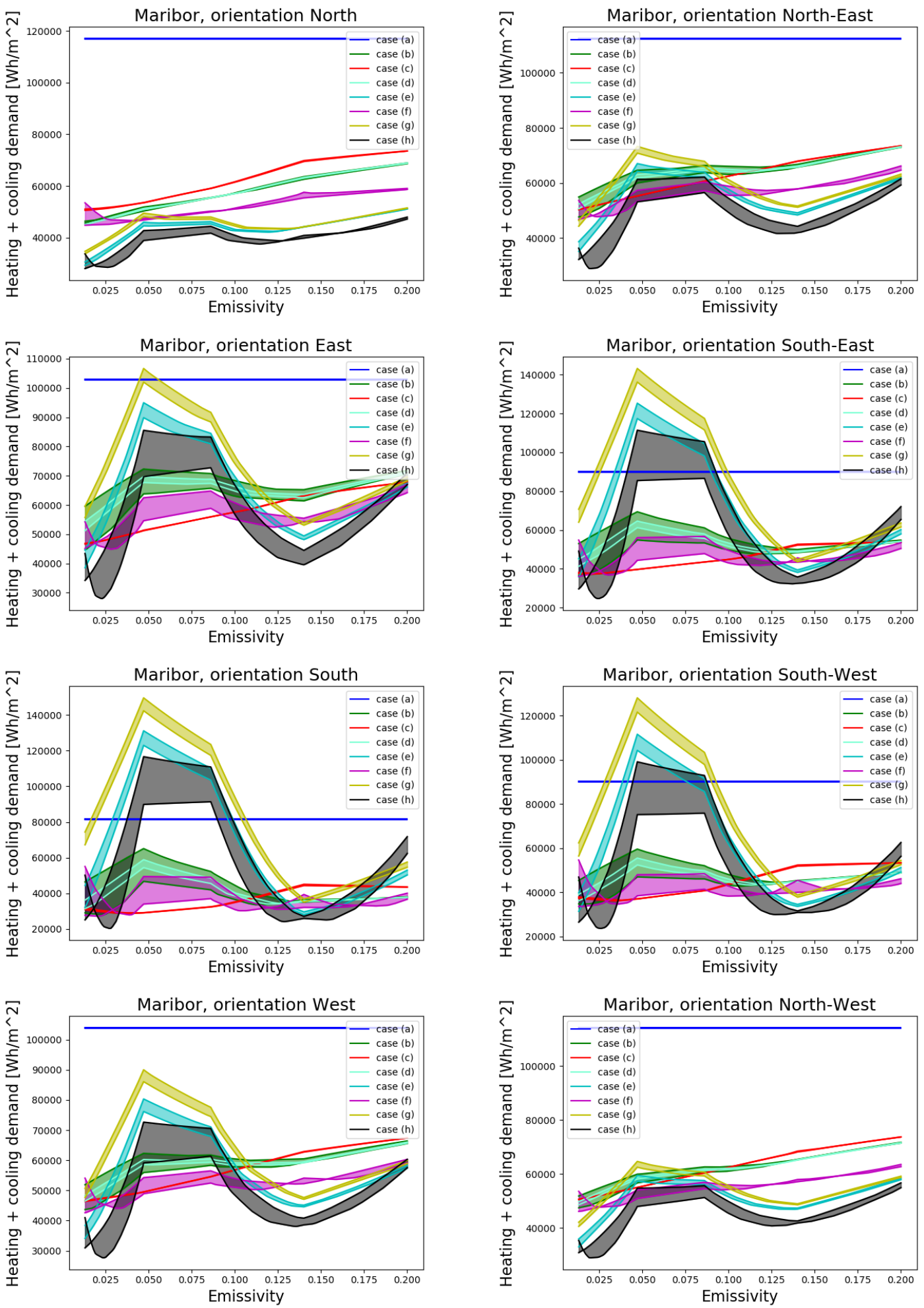

Figure 14. Annual heat loss per square meter of vertically set triple glazing system on object located at Maribor for high impedance building with high solar gains (well insulated or/and windows with large ratio of window area without shading during cooling season): (a) all panes with clear glass without low emissivity coating; (b) inner pane with low emissivity coating, other panes clear glass; (c) external pane with low emissivity coating, other panes clear glass; (d) middle pane with low emissivity coating, other panes clear glass; (e) inner pane clear glass, other panes with low emissivity coating; (f) external pane clear glass, other panes with low emissivity coating; (g) middle pane with clear glass, other panes with low emissivity coating; (h) all panes with low emissivity coating. As in case (a) there is no low-emissivity pane, the glazing has fixed emissivity and therefore the results do not vary with the emissivity. Different cases include low-emissivity glass with different values of reflectance. 

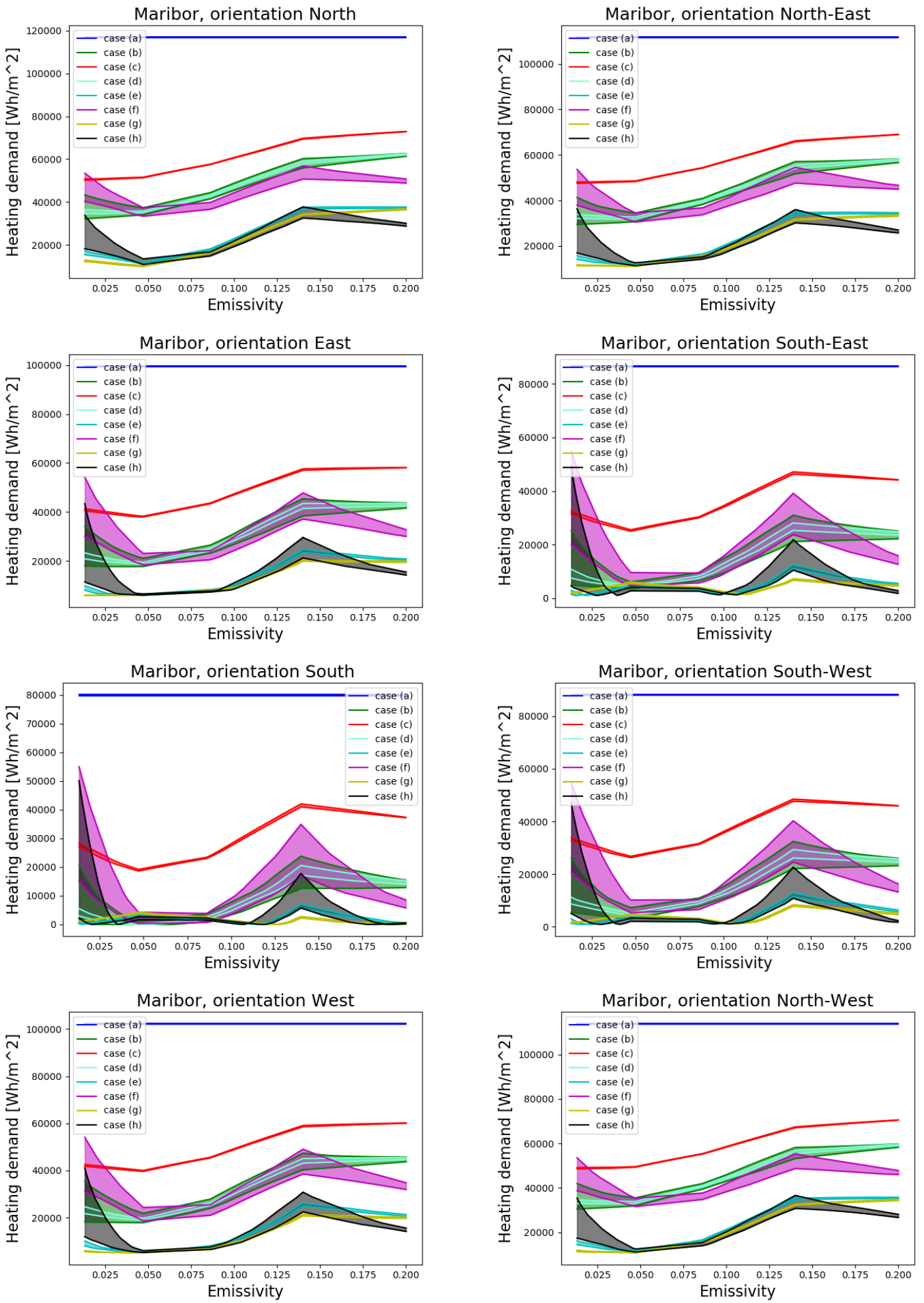

Figure 15. Annual heat loss per square meter of vertically set triple glazing system on object located at Maribor for high impedance building with high solar gains (well insulated or/and windows with large ratio of window area with shading factor 0.2 during cooling season): (a) all panes with clear glass without low emissivity coating; (b) inner pane with low emissivity coating, other panes clear glass; (c) external pane with low emissivity coating, other panes clear glass; (d) middle pane with low emissivity coating, other panes clear glass; (e) inner pane clear glass, other panes with low emissivity coating; (f) external pane clear glass, other panes with low emissivity coating; (g) middle pane with clear glass, other panes with low emissivity coating; (h) all panes with low emissivity coating. As in case (a) there is no low-emissivity pane, the glazing has fixed emissivity and therefore the results do not vary with the emissivity. Different cases include low-emissivity glass with different values of reflectance. 

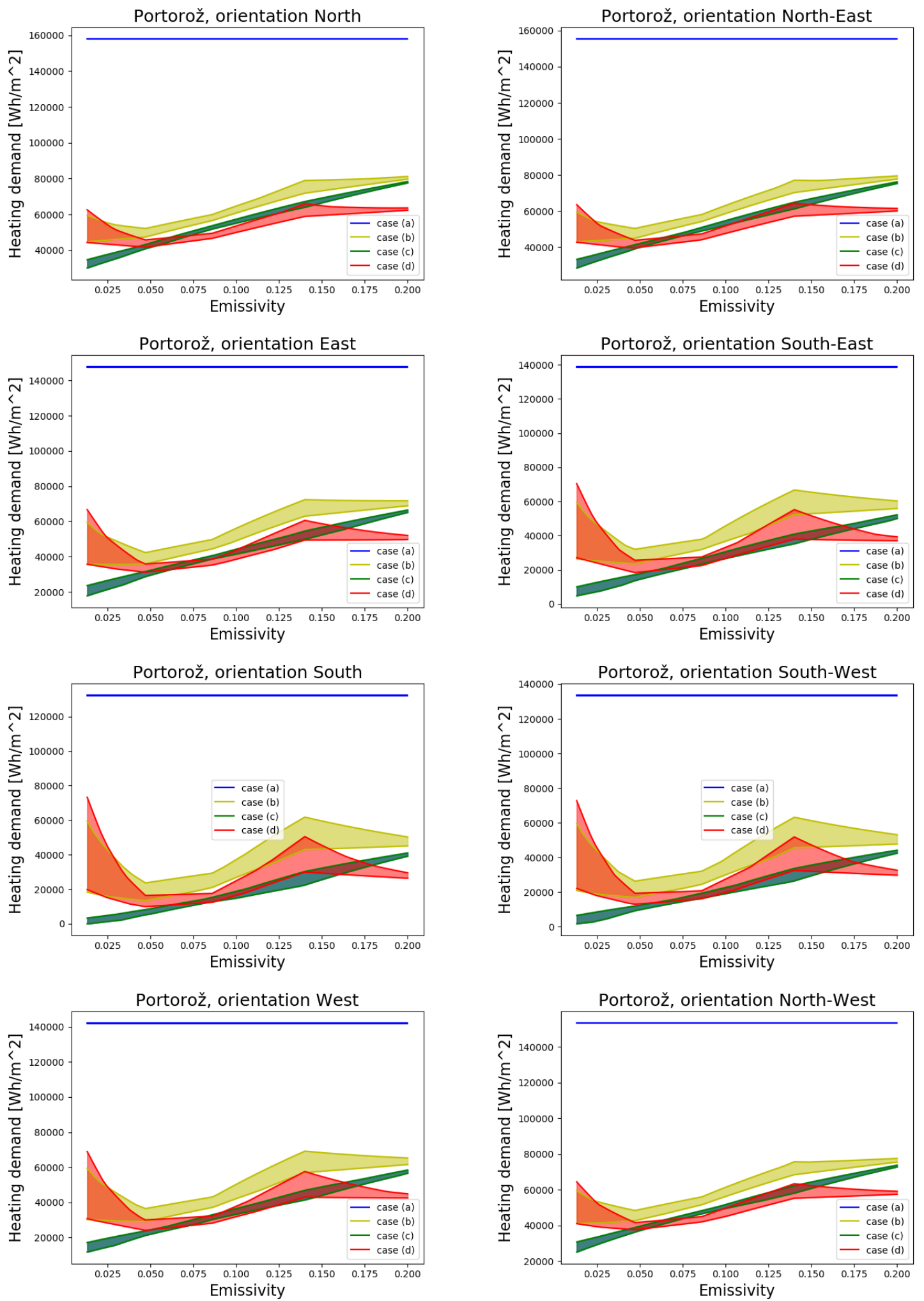

Figure 16. Annual heat loss per square meter of vertically set double glazing system on object located at Maribor for high impedance building with low solar gains (badly insulated or/and windows with small ratio of window area): (a) both panes with highest transmittance (clear glass without low emissivity coating); (b) internal pane with low emissivity coating, external pane clear glass without low emissivity coating; (c) external pane with low emissivity coating, internal pane clear glass without low emissivity coating; (d) both panes with low emissivity coating. As in case (a) there is no low-emissivity pane, the glazing has fixed emissivity and therefore the results do not vary with the emissivity. Different cases include low-emissivity glass with different values of reflectance. 

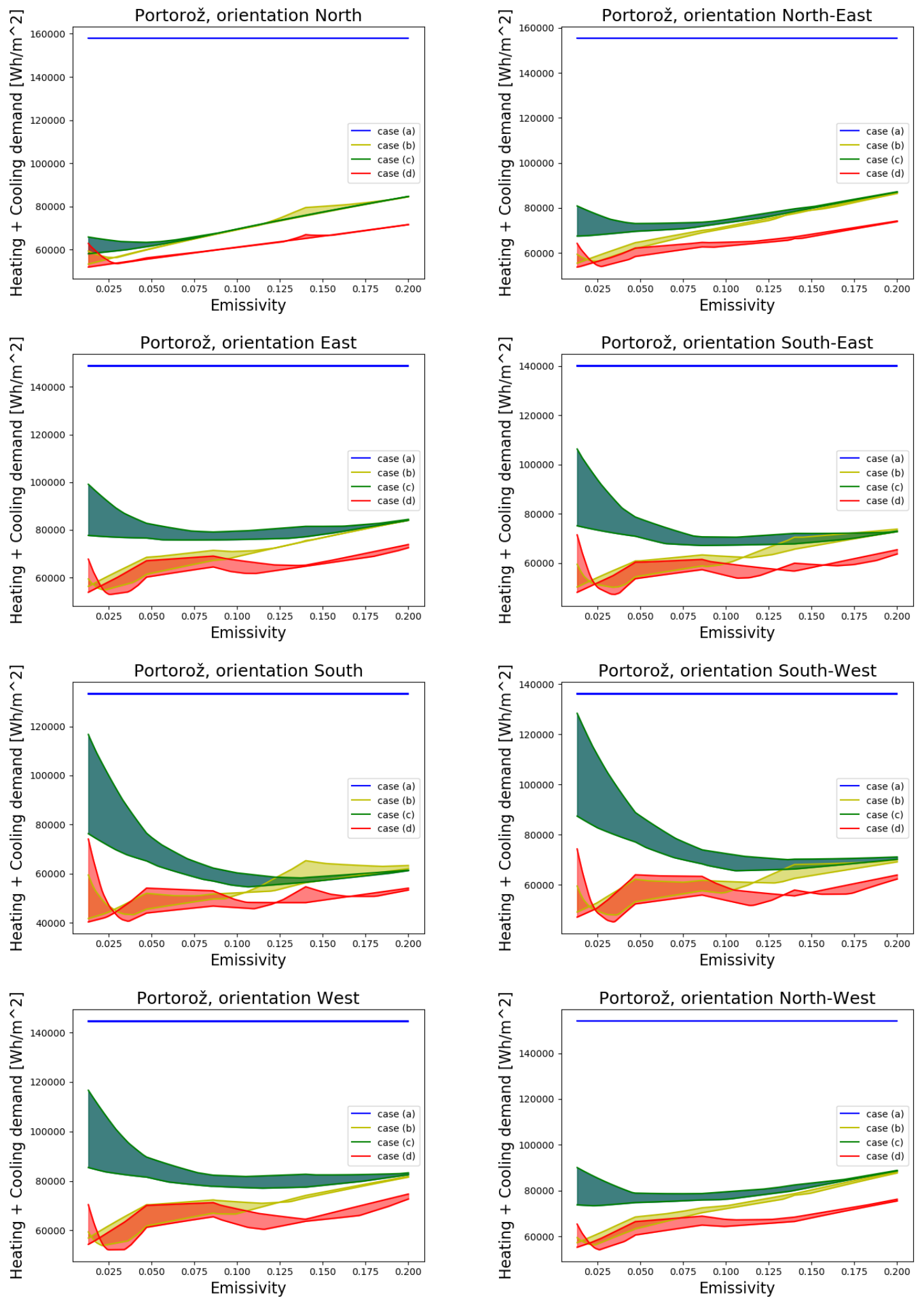

Figure 17. Annual heat loss per square meter of vertically set double glazing system on object located at Portorož for high impedance building with high solar gains (well insulated or/and windows with large ratio of window area without shading during cooling season): (a) both panes with highest transmittance (clear glass without low emissivity coating); (b) internal pane with low emissivity coating, external pane clear glass without low emissivity coating; (c) external pane with low emissivity coating, internal pane clear glass without low emissivity coating; (d) both panes with low emissivity coating. As in case (a) there is no low-emissivity pane, the glazing has fixed emissivity and therefore the results do not vary with the emissivity. Different cases include low-emissivity glass with different values of reflectance. 

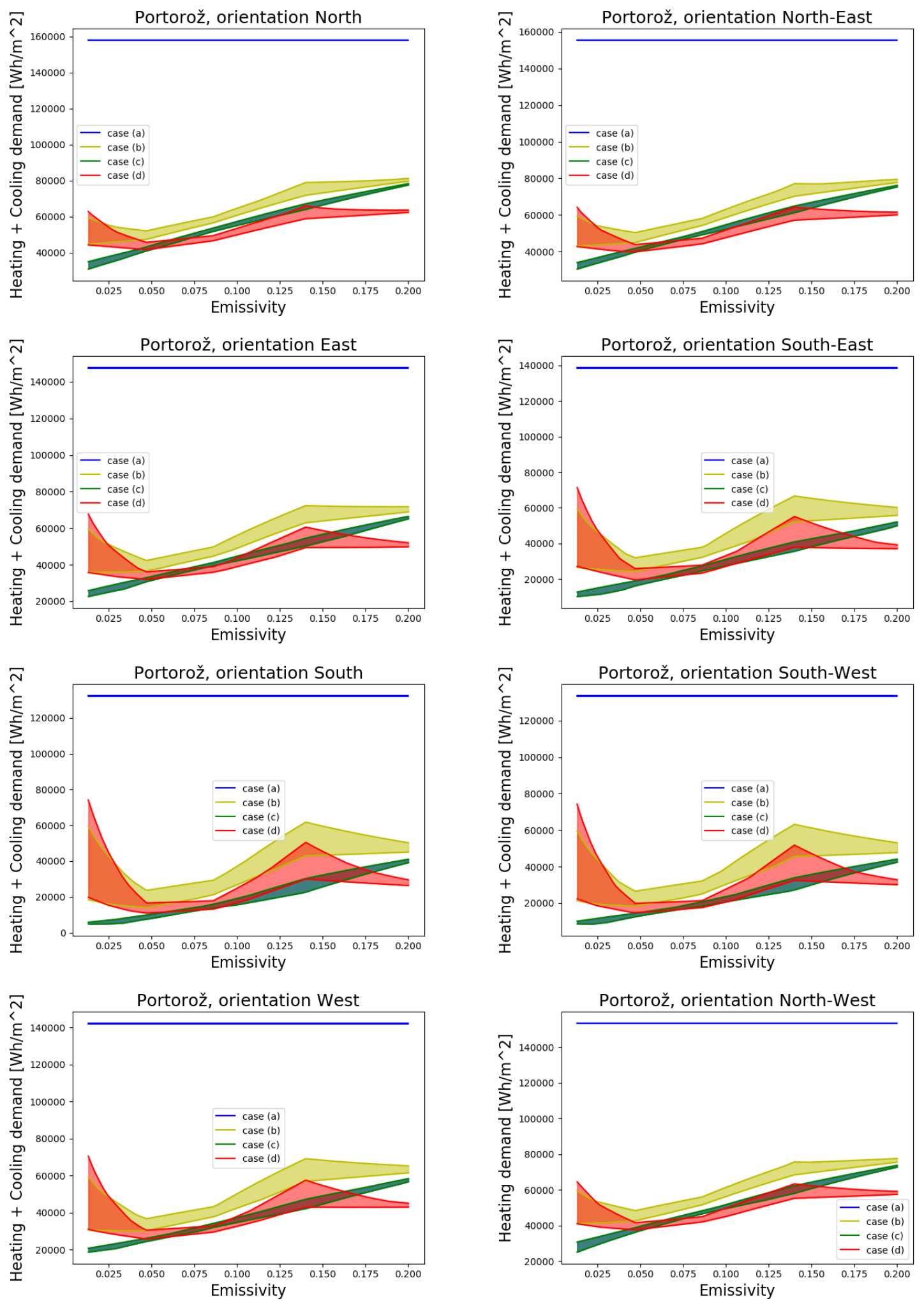

Figure 18. Annual heat loss per square meter of vertically set double glazing system on object located at Portorož for high impedance building with high solar gains (well insulated or/and windows with large ratio of window area with shading factor 0.2 during cooling season): (a) both panes with highest transmittance (clear glass without low emissivity coating); (b) internal pane with low emissivity coating, external pane clear glass without low emissivity coating; (c) external pane with low emissivity coating, internal pane clear glass without low emissivity coating; (d) both panes with low emissivity coating. As in case (a) there is no low-emissivity pane, the glazing has fixed emissivity and therefore the results do not vary with the emissivity. Different cases include low-emissivity glass with different values of reflectance. 

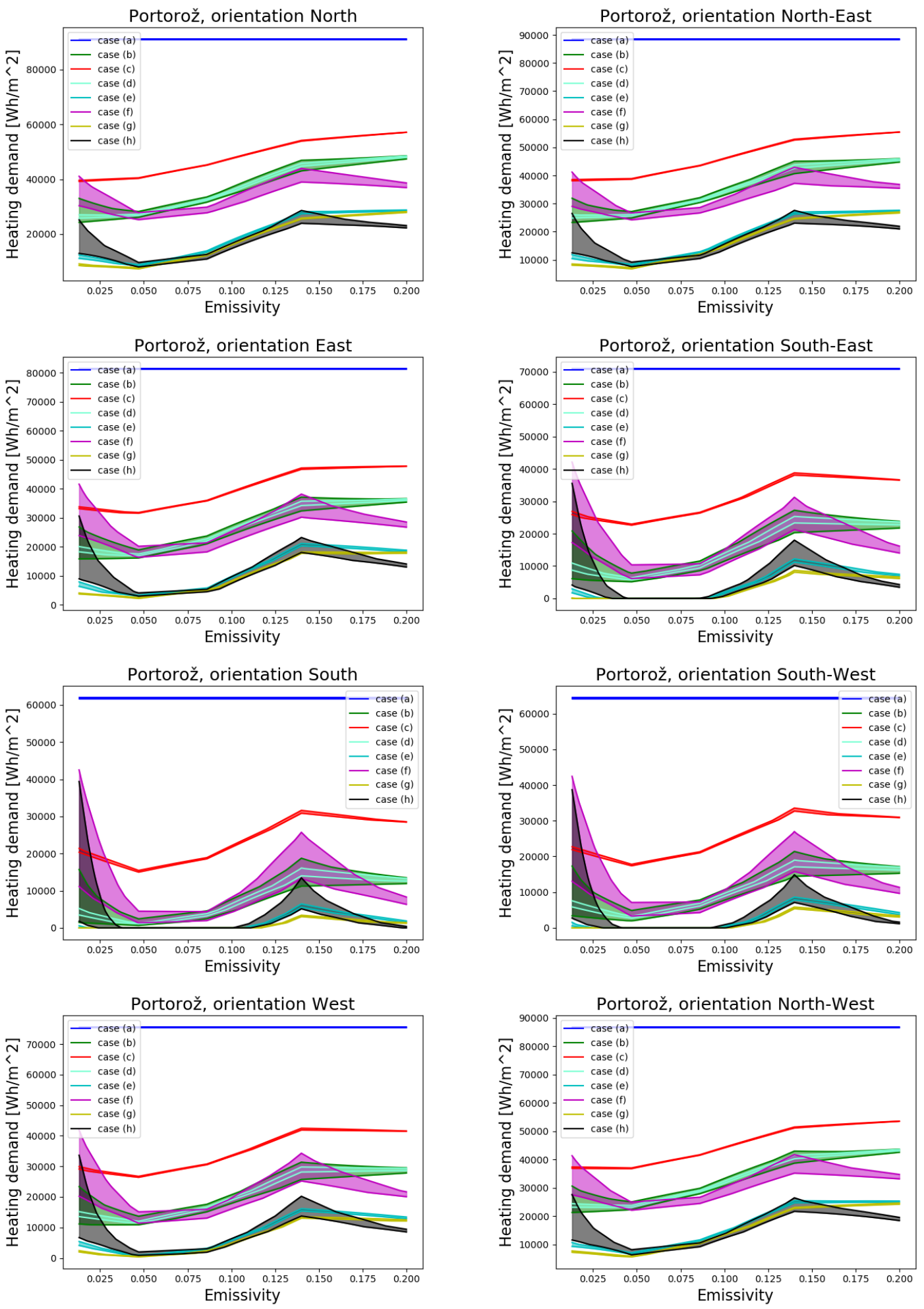

Figure 19. Annual heat loss per square meter of vertically set triple glazing system on object located at Portorož for high impedance building with low solar gains (badly insulated or/and windows with small ratio of window area): (a) all panes with clear glass without low emissivity coating; (b) inner pane with low emissivity coating, other panes clear glass; (c) external pane with low emissivity coating, other panes clear glass; (d) middle pane with low emissivity coating, other panes clear glass; (e) inner pane clear glass, other panes with low emissivity coating; (f) external pane clear glass, other panes with low emissivity coating; (g) middle pane with clear glass, other panes with low emissivity coating; (h) all panes with low emissivity coating. As in case (a) there is no low-emissivity pane, the glazing has fixed emissivity and therefore the results do not vary with the emissivity. Different cases include low-emissivity glass with different values of reflectance. 

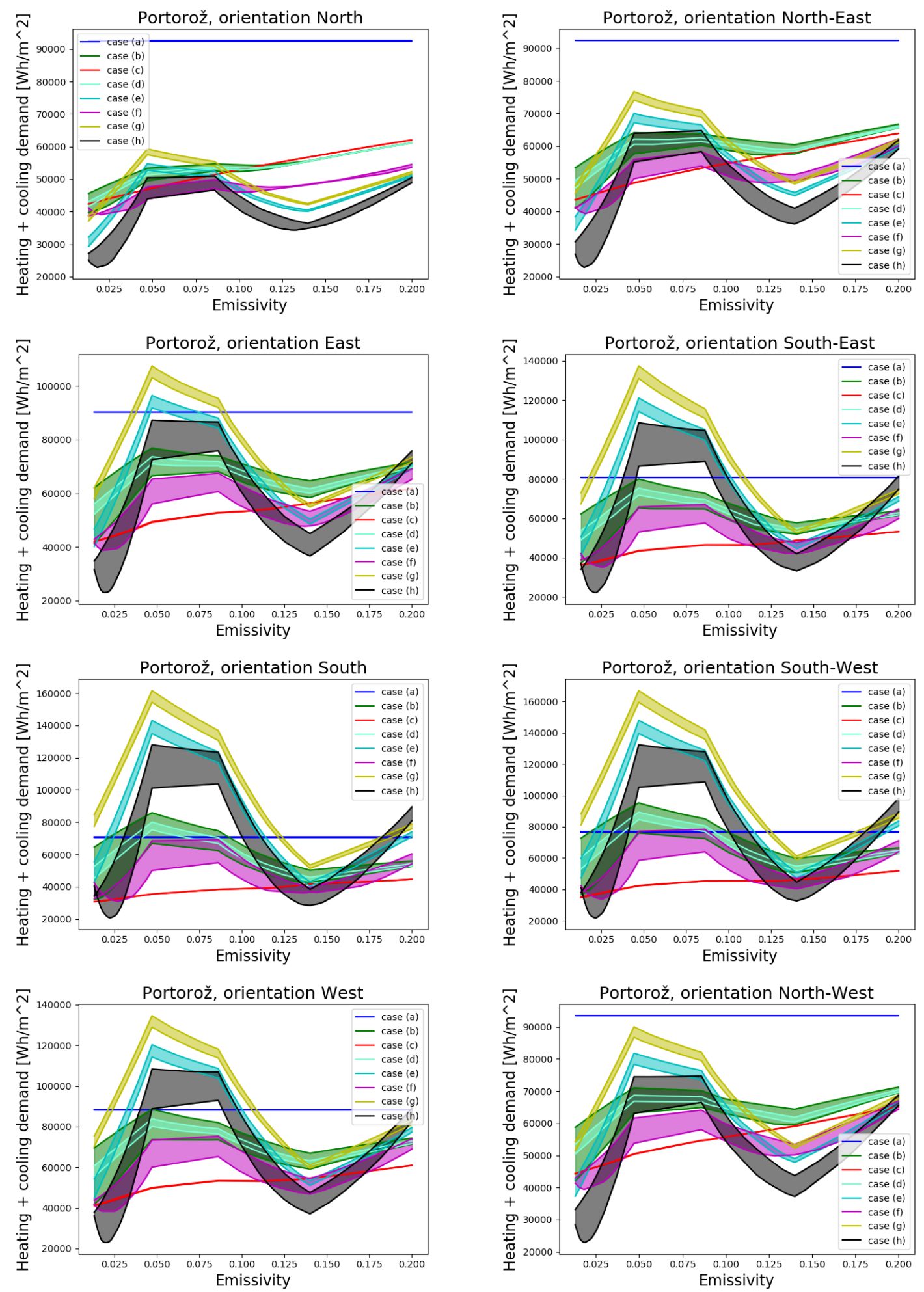

Figure 20. Annual heat loss per square meter of vertically set triple glazing system on object located at Portorož for high impedance building with high solar gains (well insulated or/and windows with large ratio of window area without shading during cooling season): (a) all panes with clear glass without low emissivity coating; (b) inner pane with low emissivity coating, other panes clear glass; (c) external pane with low emissivity coating, other panes clear glass; (d) middle pane with low emissivity coating, other panes clear glass; (e) inner pane clear glass, other panes with low emissivity coating; (f) external pane clear glass, other panes with low emissivity coating; (g) middle pane with clear glass, other panes with low emissivity coating; (h) all panes with low emissivity coating. As in case (a) there is no low-emissivity pane, the glazing has fixed emissivity and therefore the results do not vary with the emissivity. Different cases include low-emissivity glass with different values of reflectance. 

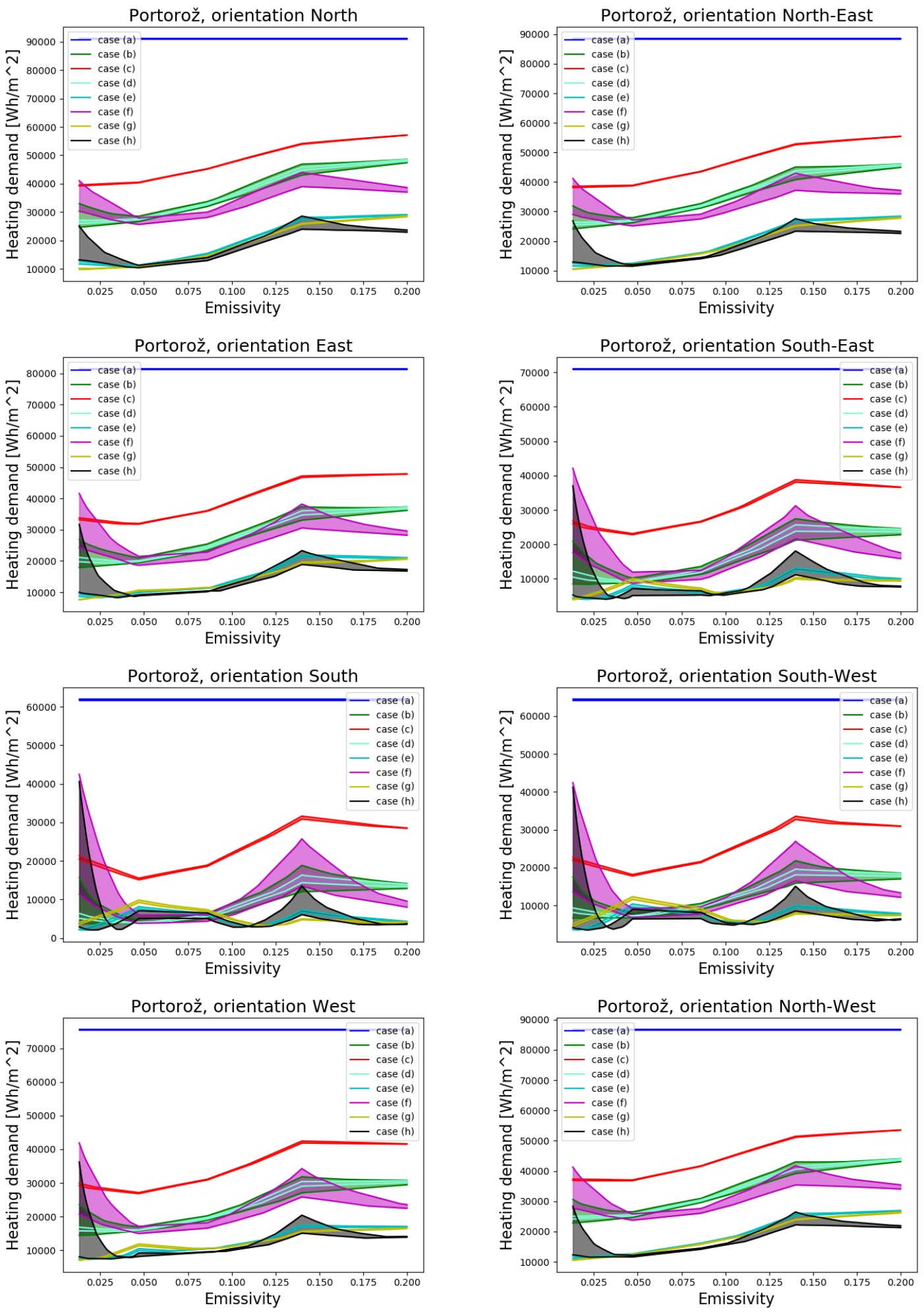

Figure 21. Annual heat loss per square meter of vertically set triple glazing system on object located at Maribor for high impedance building with high solar gains (well insulated or/and windows with large ratio of window area with shading factor 0.2 during cooling season): (a) all panes with clear glass without low emissivity coating; (b) inner pane with low emissivity coating, other panes clear glass; (c) external pane with low emissivity coating, other panes clear glass; (d) middle pane with low emissivity coating, other panes clear glass; (e) inner pane clear glass, other panes with low emissivity coating; (f) external pane clear glass, other panes with low emissivity coating; (g) middle pane with clear glass, other panes with low emissivity coating; (h) all panes with low emissivity coating. As in case (a) there is no low-emissivity pane, the glazing has fixed emissivity and therefore the results do not vary with the emissivity. Different cases include low-emissivity glass with different values of reflectance. 


\section{Conclusions}

The results of this study can give advice to window manufacturers on how to choose the right combination of glass panes with the right optical properties to achieve additional reduction of heat flux through glazing without much effort and high costs. Our results agree with the findings of Laouadi et al. [27] that low emissivity coatings can significantly reduce the heat demand, and with the findings of Kumar et al. that the low-emissivity coatings lower heat loss due to thermal transmittance but on the other hand can also reduce solar gain [26].

Nevertheless, the model has several limitations that have to be taken into account. Since the model does not include the effects of the window frame and the thermal bridge between the window and the wall, it is important to mention that if the heat transfer coefficient of the glazing is much higher than the heat transfer coefficient of the wall, the effective thermal transmittance of the glazing will be higher than predicted due to the resulting thermal bridge. Similarly, if the heat transfer coefficient of glazing is lower than the heat transfer coefficient of a wall, the effective thermal transmittance of glazing is lower than predicted. Necessary ventilation during the heating season, which is also not taken into account, increases the heating demand. During the summer season, properly planned ventilation during the cooler part of the day can help reduce cooling demand. Moreover, the threshold for the onset of cooling need not necessarily coincide with a temperature greater than $24.5^{\circ} \mathrm{C}$, but may depend on various other factors [33]. It should also be noted that cooling demand is expected to increase in the future due to the projected temperature increase caused by $\mathrm{CO}_{2}$ emissions [34]. In addition, the energy density of incident solar radiation may differ from the data in the Tables 1-3 due to various objects in the vicinity of the building (such as trees, other buildings, etc.). Moreover, the model does not correctly predict the optical properties of the glazing for the direction of the solar rays with high angle of incidence (rays almost parallel to the glazing). Finally, cooling and heating requirements are not the only factors that should be considered when deciding on the best glazing. Factors such as glare, condensation and acoustic properties must also be taken into account. Glare can be a nuisance factor, especially in winter when the sun is low and there is snow. In this case, shades must be used which unfortunately leads to reduction of solar gain. Condensation is prevented by using glazing with low heat transfer coefficients, which is not at odds with reducing heating and cooling requirements. Acoustic glazing is achieved by using panes with different thicknesses, which does not significantly affect the heating and cooling demand.

Funding: This research received no external funding.

Data Availability Statement: The data on glass panes can be found source program Windows that can be downloaded form the link https:/ / windows.lbl.gov/software/window. The data on solar radiation can be downloaded from the link http:/ / meteo.arso.gov.si/met/sl/climate/tables/.

Conflicts of Interest: The author declares no conflict of interest.

$\begin{aligned} & \text { Abbreviations } \\ & \text { The following abbreviations are used in this manuscript: }\end{aligned}$
$\begin{array}{ll}\text { low-e or low- } \varepsilon & \text { low emissivity } \\ \text { IR } & \text { infrared } \\ \text { e or } \epsilon & \text { emissivity } \\ U & \text { heat transfer coefficient } \\ R_{g} & \text { thermal resistance of air gap } \\ \text { N } & \text { North } \\ \text { S } & \text { South } \\ \text { W } & \text { West } \\ \text { E } & \text { East } \\ \text { NE } & \text { North-East } \\ \text { SE } & \text { South-East } \\ \text { NW } & \text { North-West } \\ \text { SW } & \text { South.West }\end{array}$




\section{References}

1. Detsi, M.; Manolitsis, A.; Atsonios, I.; Mandilaras, I.; Founti, M. Energy Savings in an Office Building with High WWR Using Glazing Systems Combining Thermochromic and Electrochromic Layers. Energies 2020, 13, 3020. [CrossRef]

2. Zielinska-Dabkowska, K. M.; Xavia, K. Protect Our Right to Light. Nature 2019, 568, 451-453. [CrossRef]

3. Finnegan, M. C.; Solomon, L. Z. Work attitudes in windowed vs. windowless environments. J. Soc. Psychol. 1981, 115, $291-292$. [CrossRef]

4. Leather, P.; Pyrgas, M.; Beale, D.; Lawrence, C. Windows in the Workplace: Sunlight, View, and Occupational Stress. Environ. Behav. 1998, 30, 739-762. [CrossRef]

5. Pariafsai, F. A review of design considerations in glass buildings. Front. Archit. Res. 2016, 5, 171-193. [CrossRef]

6. Faizi, F.; Yazdizad, A.; Rezaei, F. Classification of Double Skin Façade and Their Function to Reduce Energy Consumption and create sustainability in Buildings Energy Saving in District Heating Systems View project Classification of Double Skin Façade and Their Function to Reduce Energy Consumption and create sustainability in Buildings. In Proceedings of the 2nd International Congress on Structure, Architecture and Urban Development, Tabriz, Iran, 16-18 December 2014.

7. Shameri, M.A.; Alghoul, M.A.; Sopian, K.; Zain, M.F.M.; Elayeb, O. Perspectives of double skin façade systems in buildings and energy saving. Renew. Sustain. Energy Rev. 2011, 15, 1468-1475. [CrossRef]

8. Pérez-Lombard, L.; Ortiz, J.; Pout, C.; A review on buildings energy consumption information. Energy Build 2008, 40, 394-398. [CrossRef]

9. Rezaei, S.D.; Shannigrahi, S.; Ramakrishna, S. A review of conventional, advanced, and smart glazing technologies and materials for improving indoor environment. Sol. Energy Mater. Sol. Cells 2017, 159, 26-51. [CrossRef]

10. Selkowitz, S. Thermal performance of insulating window systems. In Proceedings of the ASHRAE 1979 Annual Meeting, Detroit, MI, USA, 24-28 June 1979.

11. Ochoa, C.E.; Aries, M.B.C.; van Loenen, E.J.; Hensen, J.L.M. Considerations on design optimization criteria for windows providing low energy consumption and high visual comfort. Appl. Energy 2012, 95, 238-245. [CrossRef]

12. Sbar, N.L.; Podbelski L.; Yang, H.M.; Pease, B. Electrochromic dynamic windows for office buildings. Int. J. Sustain. Built Environ. 2012, 1, 125-139. [CrossRef]

13. Dussault, J.M.; Gosselin, L. Office buildings with electrochromic windows: A sensitivity analysis of design parameters on energy performance, and thermal and visual comfort. Energy Build. 2017, 153, 50-62. [CrossRef]

14. Tavares, P.; Bernardo, H.; Gaspar, A.; Martins, A. Control criteria of electrochromic glasses for energy savings in mediterranean buildings refurbishment. Sol. Energy 2016, 134, 236-250. [CrossRef]

15. Aldawoud, A. Conventional fixed shading devices in comparison to an electrochromic glazing system in hot, dry climate. Energy Build. 2013, 59, 104-110. [CrossRef]

16. Jamrozik, A.; Clements, N.; Hasan, S.S.; Zhao, J.; Zhang, R.; Campanella, C.; Loftness, V.; Porter, P.; Ly, S.; Wang, S.; et al. Access to daylight and view in an office improves cognitive performance and satisfaction and reduces eyestrain: A controlled crossover study. Build. Environ. 2019, 165, 106379. [CrossRef]

17. Papaefthimiou, S. Chromogenic technologies: Towards the realization of smart electrochromic glazing for energy-saving applications in buildings. Adv. Build. Energy Res. 2010, 4, 77-126. [CrossRef]

18. Liang, R.; Sun, Y.; Aburas, M.; Wilson, R.; Wu, Y. Evaluation of the thermal and optical performance of thermochromic windows for office buildings in China. Energy Build. 2018, 176, 216-231. [CrossRef]

19. Saeli, M.; Piccirillo, C.; Parkin, I.P.; Binions, R.; Ridley, I. Energy modelling studies of thermochromic glazing. Energy Build. 2010, 42, 1666-1673. [CrossRef]

20. Allen, K.; Connelly, K.; Rutherford, P.; Wu, Y. Smart windows-Dynamic control of building energy performance. Energy Build. 2017, 139, 535-546. [CrossRef]

21. Hoffmann, S.; Lee, E.S.; Clavero, C. Examination of the technical potential of near-infrared switching thermochromic windows for commercial building applications. Sol. Energy Mater. Sol. Cells 2014, 123, 65-80. [CrossRef]

22. Pinterič M. Building Physics, From Physical Principles to International Standards; Springer International Publishing: Cham, Switzerland, 2017; ISBN 978-3-319-57483-7.

23. Mitchell, R.; Kohler, C.; Curcija, D.; Zhu, L; Vidanovic, S.; Czarnecki, S.; Arasteh, D. Window Version 7; Lawrence Berkeley National Laboratory: Berkeley, CA, USA, 2019. Available online: https://windows.lbl.gov/software/window (accessed on 16 March 2020).

24. Aguilar, J.O.; Xamán, J.; Olazo-Gómez, Y.; Hernández-López, I.; Becerra, G.; Jaramillo, O.A. Thermal performance of a room with a double glazing window using glazing available in Mexican market. Appl. Therm. Eng. 2017, 119, 505-515. [CrossRef]

25. Li, C.; Tan, J.; Chow, T.T.; Qiu, Z. Experimental and theoretical study on the effect of window films on building energy consumption. Energy Build. 2015, 102, 129-138. [CrossRef]

26. Kumar K.G.; Saboor G.S.; Kumar V.; Kim K.H.; Babu, A.T.P. Experimental and theoretical studies of various solar control window glasses for the reduction of cooling and heating loads in buildings across different climatic regions. Energy Build. 2018, 173, 326-336.

27. Laouadi A.; Galasiu, A.D.; Swinton, M.C.; Armstrong, M.; Szadkowski, F. Field Performance of Exterior Solar Shadings for Residential Windows: Winter Results. In Proceedings of the 12th Canadian Conference on Building Science and Technology, Montréal, QC, Canda, 6-8 May 2009; pp. 197-210. 
28. ISO 18292:2011, Energy Performance of Fenestration Systems for Residental Buildings—Calculation Procedure; International Organization for Standardization: Geneva, Switzerland, 2011.

29. ISO 13790:2008, Energy Performance of Buildings_Calculation of Energy Use for Space Heating and Cooling; International Organization for Standardization: Geneva, Switzerland, 2008.

30. Available online: http://meteo.arso.gov.si/met/sl/climate/tables/ (accessed on 24 August 2021).

31. EN 673:1997, Glass in Building_Determination of Heat Transfer Coefficient (U Value)_Calculation Method; European Committee for Standardization (CEN): Brussels, Belgium, 1997.

32. Available online: https:/ / glassforeurope.com/about-us/members/ (accessed on 16 March 2020).

33. Lomas, K.J.; Porritt, S.M. Overheating in buildings: Lessons from research. Build. Res. Inf. 2017, 45, 1-18. [CrossRef]

34. Available online: http:// kazalci.arso.gov.si/en/content/heating-and-cooling-degree-days (accessed on 22 October 2021). 